\title{
MANUFACTURER'S CHANNEL SELECTION IN A CAPITAL-CONSTRAINED SUPPLY CHAIN UNDER BARGAINING GAME
}

\author{
QIANG YAN* AND FANGYU YE
}

\begin{abstract}
In the context of a capital-constrained supply chain, we examine how a direct channel added by a manufacturer influences the players' optimal decisions and profits under bargaining game. The capital-constrained retailer adopts a type of hybrid financing scheme including bank credit and equity financing to alleviate its capital shortage. We characterize the equilibrium results under different sales channels, and examine the impacts of the bank loans ratio and bargaining power on the players' optimal decisions. The conditions of the equilibrium channel choices are derived. We find that if the retailer's bank loans ratio in the retail channel is beyond a certain threshold, a dual-channel structure can enhance the profits of the manufacturer and supply chain. The retailer, however, will benefit from the direct channel when its bank loans ratio in the retail channel is below a certain threshold. We further demonstrate that a dual-channel structure can reduce the degree of double marginalization of the overall supply chain. In addition, to solve the potential channel conflict, a bilateral payment mechanism is developed to achieve Pareto improvement for both players. Numerical examples are included to illustrate the major results of the paper.
\end{abstract}

Mathematics Subject Classification. 35J20, 35J25, 35J60.

Received July 27, 2019. Accepted July 24, 2020.

\section{INTRODUCTION}

With the rapid development of e-commerce, many manufacturers who distribute their products only through traditional retail outlets engage in online channels. Some large-sized manufacturers (e.g., IBM, Adidas, Nike and Dell) now sell directly online to consumers (see [6]). According to Chen et al. [13], consumers in the U.S. spent more than $\$ 89$ billion on shopping online in the last quarter of 2015. Sales to customers are traditionally through retail outlets, but a direct channel allows a manufacturer to sell directly to the customers with great efficiency. With a dual-channel structure, consumers have options of purchasing from either a retail channel or a direct channel. The degree to which the customer accepts the retail or direct channel is related to the nature of the product and the customers' individual preferences. Nowadays there are three typical channel structures that a manufacturer can adopt to sell its products: a manufacturer-retailer channel, a manufacturer-direct channel, a dual-channel with both retail and direct channels (see [38]). The selection of distribution channel affects the pricing decisions and profits of all players. Many large manufacturers who distribute their products only through

Keywords. Capital constraint, channel structure, bargaining, hybrid financing.

School of Business Administration, Hunan University, Changsha, Hunan 410082, P.R. China.

*Corresponding author: 15773135246@163.com 
retailers face a common problem that whether to add a direct channel or not. Therefore, channel structure is becoming a critical issue for supply chain management.

Some scholars show that the degree of product substitution, production cost, the firms' bargaining powers are important factors that influence the channel structure choice (see $[4,24,38]$ ). Further, in today's real business, firms' optimal channel structure decisions are also related to capital constraints. When the upstream manufacturers sell through a retail channel, the downstream retailers may face capital constraints, which will significantly influence the supply chain performance. Most papers focus on the single financing strategy including bank credit or trade credit (see $[7,14,45,48]$ ). However, hybrid financing strategies also widely exist in business markets. In practice, many small and medium-sized enterprises (SMEs) with capital constraints can only obtain partial financial supports from bank market due to low credit rating, and the remaining may be resorted to external investors (see $[22,31,37,47]$ ). For example, the bike-sharing giant Mobike financed from banks and external investors to deal with capital shortage since its inception in 2016. During Oct. 2016 to Jun. 2017, Mobike had received more than $\$ 1$ bn from some large-sized enterprises such as CMBC, JOY Capital, Vertex, and Hillhose Capital. Therefore, we extend the extant literature by considering the situation that the capital constrained player adopts a hybrid financing scheme including bank credit financing and equity financing.

In addition to capital constraints, some studies find that bargaining power significantly influences the firms' market competition behavior in supply chains (see [23,38]). Most of the studies focus on the negotiation in a decentralized framework. The contract parameter is unilaterally determined by one of the players, which is highly impractical for different reasons (see [35]). However, numerous empirical evidences suggest that bilateral bargaining process would be more realistic, and each player could exert some influence in term of price and order decisions (see [52]). For example, as the dominant retailer for many suppliers such as Revlon and Disney, Wal-Mart generally acquires lower prices and longer delay periods for payment. As a result, Wal-Mart's suppliers often complain that Wal-Mart gets excessive channel profits (see [27]). In order to improve their own profits, the suppliers often bargain with Wal-Mart over the wholesale prices. Therefore, we apply a Nash bargaining framework to explore the interaction between the enterprises.

Motivated by the above cases, we seek to address the following questions. (i) In present of the single retail channel, when the manufacturer should add a direct channel? (ii) How will the channel structure changes affect the profits of the manufacturer, the retailer and the supply chain? (iii) What are the impacts of some key factors (e.g., the bargaining power and the retailer's bank loans ratio) on the equilibrium results?

To answer these questions, in this paper, we consider a two-echelon supply chain with a manufacturer and a capital constrained retailer, where the manufacturer decides whether to add a direct channel in competition with the traditional retail channel. Our paper is distinct in that we incorporate the equity financing into our model, enabling us to investigate the impact of the bank loans ratio on the players' optimal decisions and profits. Moreover, we consider the bargaining process in a capital constrained supply chain, which is neglected by almost all extant literature on the channel structure choice (see $[2,19,32,40,49])$. Further, a bilateral payment mechanism is proposed to solve the potential channel conflict between two players.

The rest of this paper is organized as follows. Section 2 reviews the related literature. Section 3 introduces our model in detail. Section 4 derives the equilibrium results of each sales channel. Section 5 analyses the manufacturer's optimal channel choice and investigates how channel structure changes affect players' profits. An extension of the main model is discussed in Section 6. Section 7 concludes and presents the management insights. All proofs are presented in the Appendix.

\section{Literature REVIEW}

Our work incorporates supply chain financing with supply chain operations, and is closely related to three aspects of research: (i) channel selection, (ii) supply chain financing, and (iii) bargaining game. 


\subsection{Channel selection}

A number of researches on channel structure have shown that combining a direct channel with a traditional retail channel may have several advantages (see $[5,13,30,32]$ ). Cattani et al. [8] analyze a scenario that a manufacturer adds a direct channel in competition with the traditional retail channel. The manufacturer commits a specific equal-pricing strategy that the retail price in the direct channel equals the retailer's price in the retail channel. It finds that this strategy is beneficial to all players. Cai [6] investigates the influence of channel structures and channel coordination on the supplier, the retailer, and the entire supply chain. In the channeladding Pareto zone, both the supplier and the retailer benefit from adding a direct channel to the traditional retail channel. Wang et al. [41] investigate the optimal channel structures for selling new and remanufactured products. It finds that the manufacturer prefers to differentiate new and remanufactured products by opening a direct channel. However, the dual-channel strategy may also benefit the retailer and the total supply chain in some situations. Chen et al. [13] show that adding a direct channel always benefits both the manufacturer and the supply chain, compared to the traditional retail channel. The retailer, however, will benefit from the direct channel only when the maximum sales in the retail channel are high. A retailer's margin contract is proposed to benefit both players. However, differ from the findings above, some researchers show that whether the manufacturer adds a direct (online) channel depends on the specific conditions. For example, Chen et al. [11] employ a Stackelberg game model to examine a manufacturer's pricing strategies in a dual-channel supply chain. They propose the conditions that both the manufacturer and the retailer prefer the dual-channel structure. Ding et al. [18] also show that it is optimal for the manufacturer to operate dual channels under some conditions.

\subsection{Supply chain financing}

Many studies focus on the capital constraints under bank credit financing (BCF) and trade credit financing (TCF). In term of BCF, Jing et al. [28] suggest that BCF outperforms TCF when the manufacturer's production cost is beyond a certain threshold. Some scholars show that the retailer's initial capital level has a significant influence on the players' decisions (see [10,16]). As shown in Chen [10], the capital-constrained retailer prefers to borrow from the bank if its initial capital level is relatively low. Yan et al. [44] consider a mixed financing scheme by combining BCF with TCF, where the manufacturer provides partial credit guarantee to the retailer. It shows that the wholesale price contract with partial credit guarantee may realize supply chain coordination. According to Alan and Gaur [1], under the uncertain demand market, the bankruptcy cost and demand information asymmetry have significant influences on the bank's investment decision.

Some scholars also focus on the capital constraints under TCF. For example, Kouvelis and Zhao [29] point out that the capital constrained retailer prefers TCF to BCF if offered an optimally structured scheme. Chern et al. [9] show that TCF can not only attract new buyers but also avoid lasting price competition. Chen [12] considers a trade credit with cheaper cost than a bank credit and set the bank credit cost as the upper bound of trade credit price. In this case, TCF is the unique financing equilibrium and both players can earn more under TCF than BCF. Recently, Chod et al. [15] examine the impact of competition among suppliers on their willingness to provide TCF. Wu et al. [43] consider a trade credit model with asymmetric competing retailers in which one of retailers faces capital shortage.

In addition to BCF and TCF, other financing schemes such as equity financing or third-party platform financing (3PF), are available to capital constrained firms (see [22,37,52]). According to Yang et al. [47], the firms that drop out of the supply chain can return to the market through equity financing. Wang et al. [42] consider the situation that the online retailers can finance from the bank market or an electronic business platform to fund their business. Recently, Zhen et al. [51] study the manufacturer's financing strategy under three different financing schemes such as $\mathrm{BCF}, 3 \mathrm{PF}$ and retailer credit financing.

\subsection{Bargaining game}

The bargaining process significantly affects the players' optimal decisions. Ma et al. [36] investigate the effects of the players' bargaining powers and risk attitudes on the supply chain efficiency. They find that the retailer's 
TABLE 1. Related studies.

\begin{tabular}{llll}
\hline \hline Literature & Financing scheme & Game model & Dual-channel supply chain \\
\hline Yang et al. $[50]$ & $\mathrm{NF}$ & Bargaining game & $\sqrt{ }$ \\
Qing et al. $[38]$ & $\mathrm{NF}$ & Bargaining game & $\sqrt{ }$ \\
Huang et al. $[26]$ & $\mathrm{SCG}$ & Bargaining game & $\sqrt{ }$ \\
Han et al. $[25]$ & $\mathrm{NF}$ & Bargaining game & $\sqrt{ }$ \\
Chen $[12]$ & $\mathrm{BCF} / \mathrm{TCF}$ & Stackelberg game & $\times$ \\
Kouvelis and Zhao $[29]$ & $\mathrm{BCF} / \mathrm{TCF}$ & Stackelberg game & $\times$ \\
Jing et al. $[28]$ & $\mathrm{BCF} / \mathrm{TCF}$ & Stackelberg game & $\times$ \\
Qin et al. $[39]$ & $\mathrm{TCF}$ & Stackelberg game & $\sqrt{ }$ \\
Yang et al. $[47]$ & $\mathrm{TCF} / \mathrm{BCF}+\mathrm{EF}$ & Stackelberg game & $\times$ \\
Deng et al. $[17]$ & $\mathrm{BCF} / \mathrm{RCF}$ & Stackelberg game & $\times$ \\
Li et al. $[34]$ & $\mathrm{BCF} / \mathrm{TCF} / \mathrm{BCF}+\mathrm{EF}$ & Stackelberg game & $\sqrt{ }$ \\
Yan et al. $[45]$ & $\mathrm{TCF} / \mathrm{EF}$ & Stackelberg game & $\times$ \\
Wang et al. $[42]$ & $\mathrm{BCF} / 3 \mathrm{PF}$ & Stackelberg game & $\times$ \\
Yan et al. $[46]$ & $\mathrm{RCF}$ & Stackelberg game & $\sqrt{ }$ \\
Zhen et al. $[51]$ & 3PF/BCF/RCF & Stackelberg game & $\sqrt{ }$ \\
Our paper & $\mathrm{BCF}+\mathrm{EF}$ & Bargaining game & $\sqrt{ }$ \\
\hline
\end{tabular}

Notes. The symbols NF, SCG, RCF and EF denote no-capital constraint, suppliers credit guarantee, retailer credit financing and equity financing, respectively.

bargaining power for the supply chain profit increases as she becomes more risk averse. With asymmetric demand information, Feng et al. [20] consider a dynamic bargaining game in which a seller and a buyer bargain over order quantity and wholesale price. Zhong et al. [52] consider a multistage supply chain with deterministic pricesensitive demand under bargaining process. Further, two games for pricing decisions including the bargaining game and Stackelberg game are compared. Baron et al. [3] discuss the impact of bargaining power on the supply chain. When the supply chain is not monopolistic, the coordination can be achieved if the competition intensity between supply chains is strong. Qing et al. [38] consider a supplier's capacity-allocation problem under bargaining. The supplier can allocate his production to either a single channel or a dual-channel supply chain. It shows that the optimal channel selection of the supplier hinges on the firms' production costs. Subsequently, $\mathrm{Li}$ and $\mathrm{Li}$ [33] investigate the impacts of the transshipment price and bargaining power on the optimal decisions.

Table 1 summarizes the related literature and presents a comparative analysis to highlight the contributions of our work. Our research contributes to extant literature on three folds. First, most of studies on dual-channel supply chain assume that there is no capital constraint. We establish a model in which the capital constrained retailer has access to external financing to fund its business. Our work complements the studies by examining the impact of external financing on the players' sales channel preferences. Second, although some studies focus on the capital constraints in the supply chain management, these studies are based on the assumption that the capital constrained players can obtain adequate financial supports from financial institutions. Few studies explore a firm's capital constraint problem with a hybrid financing scheme. Li et al. [34] consider a dual-channel supply chain with a capital constrained manufacturer. Besides BCF and TCF, the manufacturer can also utilize a hybrid financing scheme including BCF and equity financing to alleviate its capital shortage. However, they assume that the manufacturer is the Stackelberg leader and ignore how the players' bargaining powers affect the players' optimal decisions. Yang et al. [47] examine the effect of equity financing on the equilibrium evolution in a supply chain with two capital constrained retailers. The abandoned retailer may consider utilize external financing combing BCF with equity financing to return to the market. Yan et al. [45] explore the financing portfolio by combining pure supplier financing with supplier investment. The results show that it is optimal to offer financing portfolio for the supplier. This paper investigates the manufacturer's optimal decisions under bargaining when both a retail channel and a direct channel exist, which differs from Yang et al. [47] and Yan 


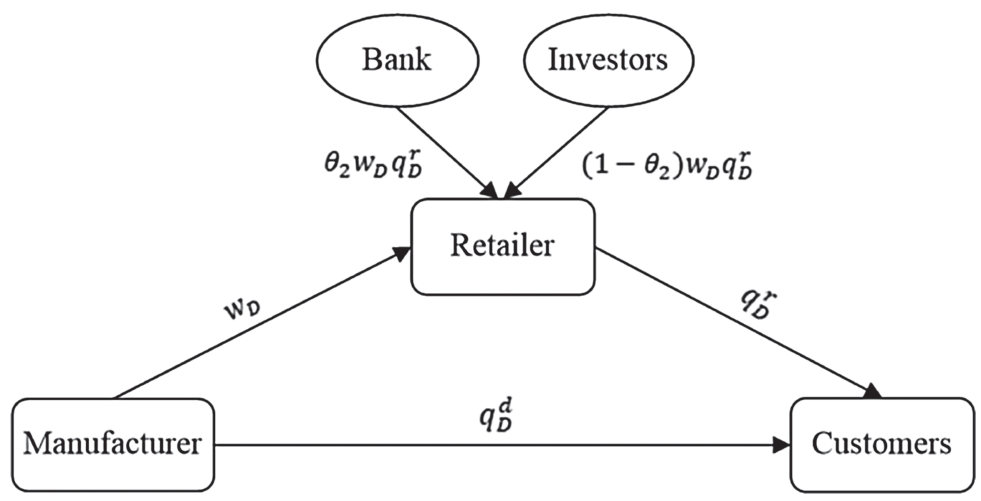

FIGURE 1. Structure for the dual-channel supply chain.

et al. [45]. Third, the results of the paper can provide some valuable insights for a dual-channel supply chain. For instance, a dual-channel structure will benefit the manufacturer when the retailer's bank loans ratio in the single retail channel is beyond a certain threshold. Further, a dual-channel structure can reduce the degree of double marginalization of the overall supply chain.

\section{MODEL DESCRIPTION AND ASSUMPTIONS}

We consider a two-echelon supply chain with an upstream manufacturer (denoted by "he") and a capital constrained retailer (denoted by "she"). The manufacturer produces a single product with constant marginal cost, which is normalized to 0 (see $[3,21]$ ). The manufacturer decides whether to add a direct channel in competition with the traditional retail channel. If the manufacturer decides to add the direct channel, channel competition occurs between the direct channel and the retail channel. In the dual channels, the manufacturer first determines the product quantity $q_{D}^{d}$ for the direct channel and bargains with the retailer over the wholesale price $w_{D}$. The retailer then declares the order quantity $q_{D}^{r}$ from the manufacturer. Figure 1 illustrates competitive structures in the dual channels.

Similar to the setting in Baron et al. [3] and Qing et al. [38], we consider the Cournot competition and the inverse demand functions can be written as follows.

$$
\begin{gathered}
p_{D}^{d}=a-q_{D}^{d}-\lambda q_{D}^{r}, \\
p_{D}^{r}=a-q_{D}^{r}-\lambda q_{D}^{d},
\end{gathered}
$$

where $a>0$ and $0 \leq \lambda \leq 1$. Parameter a represents the upper bound of market price and $\lambda$ represents the degree of market competition.

Similar to the existing literature about bargaining, we assume that the distribution of the total surplus between two players is determined by the wholesale price $w_{D}$ (see $[3,38]$ ). We adopt the asymmetric Nash bargaining solution to determine the negotiation outcome. Given $q_{D}^{r}$ and $q_{D}^{d}$ in the allocation, the choice of $w_{D}$ should maximize the following Nash product:

$$
\Phi=\left(\pi_{D}^{M}-\bar{\pi}_{D}^{M}\right)^{\beta}\left(\pi_{D}^{R}-\bar{\pi}_{D}^{R}\right)^{1-\beta},
$$

where $\bar{\pi}_{D}^{M}$ and $\bar{\pi}_{D}^{R}$ are the players' disagreement payoffs if the negotiation breaks down, and $\left(\pi_{D}^{M}-\bar{\pi}_{D}^{M}\right)$ and $\left(\pi_{D}^{R}-\bar{\pi}_{D}^{R}\right)$ are the players' incremental profits. $\beta$ represents the manufacturer's bargaining power relative to the retailer. The value of $\beta$ has significant implications for the players. An increase in a player's bargaining power will lead the other to obtain a smaller part of the total surplus (see [36]).

For clear interpretation, we list the notations in Table 2. 
TABLE 2. Notations and explanations.

\begin{tabular}{ll}
\hline \hline Notation & Explanations \\
\hline$a$ & Upper bound of market price. \\
$\lambda$ & Degree of market competition. \\
$r_{f}$ & Interest rate of bank loans. \\
$\theta_{1}$ & Retailer's bank loans ratio in the single retail channel. \\
$\theta_{2}$ & Retailer's bank loans ratio in the dual channels. \\
$\beta$ & Manufacturers bargaining power relative to the retailer. \\
$w_{i}$ & Wholesale price in the sales channel $i$, where subscript $i=R, D$ denotes \\
& the single retail channel and dual channels, respectively. \\
$q_{R}$ & Retailers order quantity of retail channel in the dual channels. \\
$q_{D}^{r}$ & Retailers order quantity of retail channel in the dual channels. \\
$q_{D}^{d}$ & Manufacturer's distribution quantity of direct channel in the dual channels. \\
$p_{R}$ & Retail price in the single retail channel. \\
$p_{D}^{r}$ & Retail price of retail channel in the dual channels. \\
$p_{D}^{d}$ & Retail price of direct channel in the dual channels. \\
$\pi_{i}^{R}$ & Retailer's profit in the channel $i$. \\
$\pi_{i}^{M}$ & Manufacturer's profit in the channel $i$. \\
$\pi_{i}^{S C}$ & Supply chain's profit in the channel $i$. \\
\hline
\end{tabular}

\section{EquiLIBRIUM ANALYSIS}

This section consists of two parts. We first present the equilibrium results of the manufacturer and the retailer under the single retail channel. Then we analyze the players' optimal decisions under the dual channels.

\subsection{The single retail channel}

In this subsection, we focus on the equilibrium analysis under the traditional retail channel. The game subsequence is as follows. In stage 1 , the manufacturer and retailer bargain over the wholesale price $w_{R}$. In stage 2 , the retailer orders its desired order quantity $q_{R}$, then borrows $\theta_{1} w_{R} q_{R}$ from the bank and finances the amount of $\left(1-\theta_{1}\right) w_{R} q_{R}$ from the investors. In stage 3 , at the end of the sales season, the retailer transfers a fraction $1-\theta_{1}$ of her profit to the equity investors. The retailer's profit is as follows:

$$
\pi_{R}^{R}=\theta_{1}\left[p_{R} q_{R}-\theta_{1} w_{R} q_{R}\left(1+r_{f}\right) .\right.
$$

where $p_{R}=a-q_{R}$.

The manufacturer receives a payment of $w_{R} q_{R}$ from the retailer at the beginning of the sales season, which is equivalent to $w_{R} q_{R}\left(1+r_{f}\right)$ at the end of the sales season if when time value is considered. Therefore, the manufacturer's profit is as follows:

$$
\pi_{R}^{M}=w_{R} q_{R}\left(1+r_{f}\right) .
$$

Following Ma et al. [36] and Qing et al. [38], given $q_{R}$, the choice of $w_{R}$ should maximize the following Nash product:

$$
\Phi_{1}=\left(\pi_{R}^{M}-\bar{\pi}_{R}^{M}\right)^{\beta}\left(\pi_{R}^{R}-\bar{\pi}_{R}^{R}\right)^{1-\beta},
$$

where $\bar{\pi}_{R}^{M}$ and $\bar{\pi}_{R}^{R}$ are the players' disagreement payoffs and in this case, $\bar{\pi}_{R}^{M}=\bar{\pi}_{R}^{R}=0 . \beta$ and $1-\beta$ are the bargaining powers for the manufacturer and the retailer, respectively.

After solving the above problems, we have the following results in Lemma 4.1.

Lemma 4.1. Under the single retail channel, the equilibrium wholesale price is $w_{R}^{*}=\frac{a \beta}{2 \theta_{1}\left(1+r_{f}\right)}$, and the equilibrium order quantity is $q_{R}^{*}=\frac{a(2-\beta)}{4}$. 
From Lemma 4.1, we further derive that the manufacturer's profits is $\pi_{R}^{M *}=\frac{a^{2} \beta(2-\beta)}{8 \theta_{1}}$ and the retailer's profit is $\pi_{R}^{R *}=\frac{\left.a^{2} \theta_{1}(2-\beta)^{2}\right)}{16}$. We find that the wholesale price increases with $\beta$, which determines the split of the total surplus. This indicates that a stronger manufacturer's bargaining power leads to a lower order quantity. Further, the retailer's order quantity is independent of $\theta_{1}$ while the manufacturer's wholesale price decreases with $\theta_{1}$. Next, we focus on the equilibrium analysis under the dual channels.

\subsection{The dual channels}

In the dual channels, two sales channels engage in competition and the game sequence is as follows. In stage 1 , the manufacturer first determines the distribution quantity $q_{D}^{d}$ in the direct channel. In stage 2 , the manufacturer bargains the wholesale price $w_{D}$ with the retailer. In stage 3 , the retailer determines its order quantity $q_{D}^{r}$, then borrows $\theta_{2} w_{D} q_{D}^{r}$ from the banks and finances the amount of $\left(1-\theta_{2}\right) w_{D} q_{D}^{r}$ from the investors. In stage 4 , at the end of the sales season, the retailer transfers a fraction $1-\theta_{2}$ of her profit as to the investors.

The retailer's profit is

$$
\pi_{D}^{R}=\theta_{2}\left[p_{D}^{r} q_{D}^{r}-\theta_{2} w_{D} q_{D}^{r}\left(1+r_{f}\right)\right] .
$$

The manufacturer's profit is

$$
\pi_{D}^{M}=p_{D}^{d} q_{D}^{d}+w_{D} q_{D}^{r}\left(1+r_{f}\right)
$$

Given $q_{D}^{r}$ and $q_{D}^{d}$, the choice of $w_{D}$ should maximize the following Nash product:

$$
\Phi_{2}=\left(\pi_{D}^{M}-\bar{\pi}_{D}^{M}\right)^{\beta}\left(\pi_{D}^{M}-\bar{\pi}_{D}^{M}\right)^{1-\beta},
$$

where $\bar{\pi}_{D}^{M}$ and $\bar{\pi}_{D}^{R}$ are the players' disagreement payoffs if the negotiation breaks down, $\bar{\pi}_{D}^{R}=0, \bar{\pi}_{D}^{M}$ is the profit the manufacturer sells only thorough direct channel.

After solving the above problems, we have the following results in Lemma 4.2.

Lemma 4.2. Under the dual channels, suppose $\theta_{2} \in\left(\frac{\lambda}{4-\lambda}, 1\right]$, then we have the following results:

$$
\begin{aligned}
w_{R}^{*} & =\frac{a\left(4 \beta-2 \theta \beta \lambda+4 \lambda \theta_{2}-2 \beta \lambda^{2}+\beta^{2} \lambda^{2}+\beta^{2} \lambda^{2} \theta_{2}-2 \beta \lambda^{2} \theta_{2}\right)}{\left(\beta^{2} \lambda^{2} \theta_{2}^{2}+2 \beta^{2} \lambda^{2} \theta_{2}+\beta^{2} \lambda^{2}-2 \beta \lambda^{2} \theta_{2}{ }^{2}-4 \beta \lambda^{2} \theta_{2}-2 \beta \lambda^{2}+8 \theta_{2}\right)\left(1+r_{f}\right)}, \\
q_{D}^{d *} & =\frac{a\left(4 \theta_{2}-2 \beta \lambda+\beta^{2} \lambda-2 \beta \lambda \theta_{2}+\beta^{2} \lambda \theta_{2}\right)}{\beta^{2} \lambda^{2} \theta_{2}^{2}+2 \beta^{2} \lambda^{2} \theta_{2}+\beta^{2} \lambda^{2}-2 \beta \lambda^{2} \theta_{2}{ }^{2}-4 \beta \lambda^{2} \theta_{2}-2 \beta \lambda^{2}+8 \theta_{2}}, \\
q_{D}^{r *} & =\frac{a \theta_{2}\left(2-\lambda-\lambda \theta_{2}\right)(2-\beta)}{\beta^{2} \lambda^{2} \theta_{2}^{2}+2 \beta^{2} \lambda^{2} \theta_{2}+\beta^{2} \lambda^{2}-2 \beta \lambda^{2} \theta_{2}^{2}-4 \beta \lambda^{2} \theta_{2}-2 \beta \lambda^{2}+8 \theta_{2}} .
\end{aligned}
$$

According to Lemma 4.2, we further derive that the manufacturer's profit is

$$
\pi_{D}^{M *}=\frac{a^{2}\left(2 \beta+2 \theta_{2}-2 \beta \lambda+\beta^{2} \lambda-\beta^{2}-2 \beta \lambda \theta_{2}+\beta^{2} \lambda \theta_{2}\right.}{\beta^{2} \lambda^{2} \theta_{2}{ }^{2}+2 \beta^{2} \lambda^{2} \theta_{2}+\beta^{2} \lambda^{2}-2 \beta \lambda^{2} \theta_{2}{ }^{2}-4 \beta \lambda^{2} \theta_{2}-2 \beta \lambda^{2}+8 \theta_{2}},
$$

and the retailer's profit is

$$
\pi_{D}^{R *}=\frac{\left.a^{2} \theta_{2}{ }^{3}\left(2-\lambda-\lambda \theta_{2}\right)^{2}(2-\beta)^{2}\right)}{\left(\beta^{2} \lambda^{2} \theta_{2}{ }^{2}+2 \beta^{2} \lambda^{2} \theta_{2}+\beta^{2} \lambda^{2}-2 \beta \lambda^{2} \theta_{2}{ }^{2}-4 \beta \lambda^{2} \theta_{2}-2 \beta \lambda^{2}+8 \theta_{2}\right)^{2}} .
$$

According to the proof of Lemma 4.2, when $\theta_{2}$ is sufficiently low, the retailer may choose a negative order quantity, which implies that the retailer will not order from the manufacturer. Therefore, the manufacturer will sell all products through the direct channel. In this case, the sales quantity in the direct channel is $\frac{a}{2}$ and the manufacturer's profit is $\frac{a^{2}}{4}$. As our focus is on the manufacturer's channel preference between the single retail channel and the dual channels, we assume $\theta_{2} \in\left(\frac{\lambda}{4-\lambda}, 1\right]$ in the following sections. Next, we analyze the impacts of the bank loans ratio and the manufacturer's bargaining power on the players' optimal decisions. 


\section{Proposition 4.3.}

(i) $\frac{\partial w_{D}^{*}}{\partial \beta}>0$; $\frac{\partial q_{D}^{d *}}{\partial \beta}<0$; When $\lambda<\frac{4}{9}$ or when $\frac{4}{9}<\lambda<\frac{\sqrt{2}}{2}$ and $\theta_{2}>\bar{\theta}$, then $\frac{\partial q_{D}^{r *}}{\partial \beta}<0$; When $\frac{4}{9} \leq \lambda<\frac{\sqrt{2}}{2}$ and $\theta_{2} \leq \bar{\theta}$ or when $\lambda \geq \frac{\sqrt{2}}{2}$, then there exists a unique $\beta_{1}$ such that $\frac{\partial q_{D}^{r *}}{\partial \beta} \geq 0$ if $\beta \leq \beta_{1}$, and $\frac{\partial \partial_{D}^{r *}}{\partial \beta}<0$ if $\beta>\beta_{1}$.

(ii) $\frac{\partial w_{D}^{*}}{\partial \theta_{2}}<0 ; \frac{\partial q_{D}^{d *}}{\partial \theta_{2}}>0$ and $\frac{\partial q_{D}^{r *}}{\partial \theta_{2}}<0$.

A stronger manufacturer's bargaining power implies a larger proportion of the total surplus, which is determined by the wholesale price. Therefore, $w_{D}^{*}$ increases with $\beta$. In the dual channels, the sales quantity in the direct channel decreases with $\beta$. The reason for this result is as follows. First, the manufacturer's direct channel sales have a lower margin cost $(0)$, while the retail channel sales have a higher margin cost $\left(\theta_{2} w_{D}\right)$. Second, for the lower-cost manufacturer in the direct channel, there are two opposite effects on his sales quantity in the direct channel due to an increased $\beta$ : a negative effect on the reduced total market demand and a positive effect on the competitive advantage from lower cost in the direct channel. Meanwhile, as $\beta$ increases, the negative effect always dominates the positive effect. Therefore, the manufacturer will lower the distribution quantity in the direct channel as $\beta$ grows. Interestingly, the relationship between the retailer's order quantity and $\beta$ depends on $\lambda$ and $\theta_{2}$. The reason for this result is similar to the manufacturer.

Proposition 4.3 shows that as the bank loans ratio grows, the wholesale price increases, the manufacturer's distribution quantity increases while the retailer's order quantity decreases. Note that a larger $\theta_{2}$ indicates that the retailer share less revenue with the investors but pays more interest to the bank. Similar to Yang et al. [47], the equity financing can be considered as a proxy for the retailer's operational costs. As $\theta_{2}$ increases, the retailer becomes less competitive in terms of costs and thus orders less. Because of the strategic interaction, the manufacturer distributes more for the direct channel.

\section{Manufacturer's optimal CHANnEL CHOICE}

In this section, we focus on the main questions of this paper: whether the manufacturer is willing to add a direct channel to compete with the traditional retail channel? Meanwhile, how the manufacturer's adding a direct channel affects the retailer's profit? Next, we first analyze the effect of adding a direct channel on the players' optimal decisions.

\section{Proposition 5.1.}

(i) When $\theta_{1} \leq \theta_{11}$, then $w_{R}^{*} \geq w_{D}^{*}$; When $\theta_{11}<\theta_{1} \leq \theta_{12}$, then there exists a unique $\theta_{21}$ such that $w_{R}^{*} \geq w_{D}^{*}$ if $\theta_{2} \geq \theta_{21}$, and $w_{R}^{*}<w_{D}^{*}$ if $\theta_{2}<\theta_{21}$; When $\theta_{1}>\theta_{12}$, then $w_{R}^{*}<w_{D}^{*}$;

(ii) $q_{R}^{*} \geq q_{D}^{r *}$;

(iii) When $\beta \leq \frac{1}{2}$ and $\lambda \geq \lambda_{1}$, then $q_{D}^{d *} \geq q_{D}^{r *}$; When $\beta \leq \frac{1}{2}$ and $\lambda<\lambda_{1}$ or when $\beta>\frac{1}{2}$, then there exists a unique $\theta_{22}$ such that $q_{D}^{d *} \geq q_{D}^{r *}$ if $\theta_{2} \geq \theta_{22}$, and $q_{D}^{d *}<q_{D}^{r *}$ if $\theta_{2}<\theta_{22}$;

(iv) $q_{D}^{d *}+q_{D}^{r *} \geq q_{R}^{*}$.

From Lemmas 4.1 and 4.2, we have $\frac{\partial w_{R}^{*}}{\partial \theta_{1}}<0$ and $\frac{\partial w_{D}^{*}}{\partial \theta_{2}}<0$. The manufacturer has the same margin cost (0) in either retail channel or dual channels, but in terms of the relationship between $w_{R}^{*}$ and $w_{D}^{*}$, we observe two determinants: $\theta_{1}$ and $\theta_{2}$. When $\theta_{1}$ is sufficiently small (large), then $w_{R}^{*}$ is always greater (lower) than $w_{D}^{*}$. When $\theta_{1}$ is medium, then $w_{R}^{*}$ is greater than $w_{D}^{*}$ if and only if $\theta_{2}$ is beyond a certain threshold $\theta_{21}$. In the dual channels, the manufacturer competes with the retailer and the direct channel will cannibalize part of the retail channel. Therefore, $q_{R}^{*} \geq q_{D}^{r *}$.

We note that the manufacturer's direct channel sales have a lower margin cost (0), while the retail channel sales have a higher margin cost $\left(\theta_{2} w_{D}\right)$. However, this does not imply that the sales quantity in the direct channel is greater than that in the retail channel. When $\beta \leq \frac{1}{2}$ and $\lambda \geq \lambda_{1}$, there will be an obvious cost advantage for the manufacturer in the direct channel. Therefore, it is beneficial for the manufacturer to sell more in the direct channel compared with the retail channel. In other cases, whether the manufacturer sells 
more in the direct channel than that in the retail channel depends on $\theta_{2}$. Since $\frac{\partial q_{D}^{d *}}{\partial \theta_{2}}>0$ and $\frac{\partial q_{D}^{r *}}{\partial \theta_{2}}>0$, then $q_{D}^{d *}$ is greater than $q_{D}^{r *}$ if $\theta_{2}$ is beyond the threshold $\theta_{22}$, but $q_{D}^{d *}$ is less than $q_{D}^{r *}$ if $\theta_{2}<\theta_{22}$.

Similar to the manufacturer's Stackelberg dual-channel supply chain (see [33]), the total demand in the dual channels is higher than that in the single retail channel, which implies that adding a direct channel can reduce the degree of double marginalization. Next, we investigate the impacts of $\theta_{1}$ and $\theta_{2}$ on the players' profits.

\section{Proposition 5.2.}

(i) $\frac{\partial \pi_{R}^{M *}}{\partial \theta_{1}}<0$ and $\frac{\partial \pi_{R}^{R *}}{\partial \theta_{1}}>0$;

(ii) There exists a unique $\bar{\theta}_{1}\left(\theta_{2}\right) \in(0,1]$ such that $\pi_{D}^{M *} \geq \pi_{R}^{M *}$ if $\theta_{1} \geq \bar{\theta}_{1}\left(\theta_{2}\right)$, and $\pi_{D}^{M *}<\pi_{R}^{M *}$ if $\theta_{1}<\bar{\theta}_{1}\left(\theta_{2}\right)$;

(iii) There exists a unique $\hat{\theta}_{1}\left(\theta_{2}\right) \in(0,1]$ such that $\pi_{D}^{R *}>\pi_{R}^{R *}$ if $\theta_{1}<\hat{\theta}_{1}\left(\theta_{2}\right)$, and $\pi_{D}^{R *} \geq \pi_{R}^{R *}$ if $\theta_{1} \leq \hat{\theta}_{1}\left(\theta_{2}\right)$.

When the retailer finances from the bank and external investors, it will increase extra cost from the interest repaid to the bank, which is related to the bank loans ratio. According to Lemma 4.1, we observe that the wholesale price decreases with $\theta_{1}$ and the order quantity is independent of $\theta_{1}$, which implies that in the retailer channel a high bank loans ratio will benefit the retailer while hurt the manufacturer. This outcome is consistent with that in Yang et al. [47] and Li et al. [34]. Therefore, it is wise for the manufacturer to encourage the retailer to borrow more from the investors. When the bank loans ratio $\theta_{1}$ is beyond a certain threshold $\left(e . g ., \theta_{1} \geq \bar{\theta}_{1}\left(\theta_{2}\right)\right)$, then the manufacturer has an incentive to add a new sales channel. However, the retailer's profit increases with $\theta_{1}$ in the retail channel. Therefore, if the bank ratio $\theta_{1}$ is below a certain threshold $\left(e . g ., \theta_{1}<\hat{\theta}_{1}\left(\theta_{2}\right)\right)$, then the retailer also prefers the dual channels. Note that if and only if $\theta_{1} \in\left[\min \left\{\bar{\theta}_{1}\left(\theta_{2}\right), \hat{\theta}_{1}\left(\theta_{2}\right)\right\}, \max \left\{\bar{\theta}_{1}\left(\theta_{2}\right), \hat{\theta}_{1}\left(\theta_{2}\right)\right\}\right]$, both players have the same channel preference.

\section{Proposition 5.3.}

(i) $\frac{\partial \pi_{D}^{M *}}{\partial \theta_{2}}<0$;

(ii) When $\theta \leq \theta_{13}$, then $\pi_{D}^{M *} \leq \pi_{R}^{M *}$; when $\theta_{13}<\theta_{1}<\theta_{14}$, then exists a unique $\theta_{23}$ such that $\pi_{D}^{M *} \geq \pi_{R}^{M *}$ if $\theta_{2} \leq \theta_{23}$, and $\pi_{D}^{M *}<\pi_{R}^{M *}$ if $\theta_{2}>\theta_{23}$; when $\theta_{1} \geq \theta_{14}$, then $\pi_{D}^{M *} \geq \pi_{R}^{M *}$.

From Proposition 5.3, the manufacturer's profit in the dual channels decreases with $\theta_{2}$. As shown in Proposition 4.3(iii), $w_{D}^{*}$ and $q_{D}^{r *}$ decrease with $\theta_{2}$ while $q_{D}^{d *}$ increases with $\theta_{2}$. Similar to the analysis detail of Proposition 4.3 , as $\theta_{2}$ grows, the negative effects of the decreased $w_{D}^{*}$ and $q_{D}^{r *}$ dominate the positive effect of the increased $q_{D}^{d *}$ on the retailer's profit. Therefore, a high bank loans ratio will hurt the manufacturer. As shown in Proposition 5.2(i), the manufacturer's profit in the retail channel decreases with $\theta_{1}$. Therefore, a sufficiently high (or low) $\theta_{1}$ will lead to a low (or high) profit for the manufacturer in the retail channel, which implies that the manufacturer's profit in the retail channel is always lower (or higher) than that in the dual channels. However, when $\theta_{1}$ is medium, the manufacturers channel choice mainly depends on $\theta_{2}$. Since $\frac{\partial \pi_{D}^{M *}}{\partial \theta_{2}}<0$, adding a direct channel will bring more profit to the manufacturer if $\theta_{2}$ is below a certain threshold $\theta_{23}$.

Regarding the retailer, it is difficult to obtain analytical results for the sensitivity analysis in terms of profits. Instead, we will present a serial of numerical examples to examine the impact of $\theta_{2}$ on the retailer's profit and channel preference. We next study the impact of adding a new channel on the supply chain's profit. We compare the supply chain's profits between the two different channel structures. It is difficult to examine the impact of $\theta_{2}$ on the supply chain's channel selection, however, according to Proposition 5.2, we obtain the following Proposition 5.4.

Proposition 5.4. Given $\beta=1$, then the supply chain's optimal sales channel is a dual-channel structure if $\theta_{1} \geq \theta_{1}^{*}$; but a single retail-channel structure if $\theta_{1}<\theta_{1}^{*}$.

According to the proof the Proposition 5.3, the supply chain's profit decreases with $\theta_{1}$ in the retail channel when $\beta=1$. Therefore, when the bank ratio $\theta_{1}$ in the retail channel is beyond a certain threshold (e.g., $\left.\theta_{1} \geq \theta_{1}^{*}\right)$, then the supply chain's optimal choice is a dual-channel structure. 


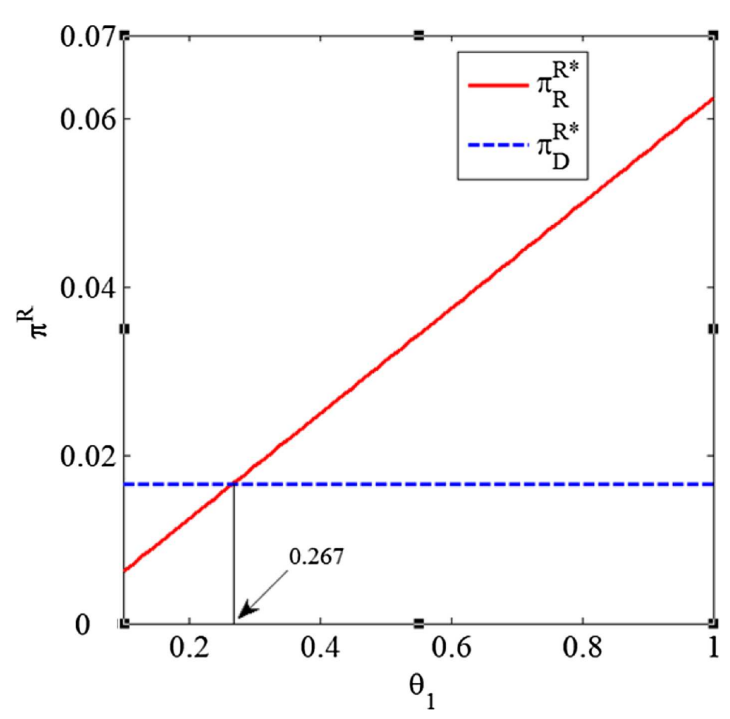

FIGURE 2. Retailer's profit changes with $\theta_{1}$.

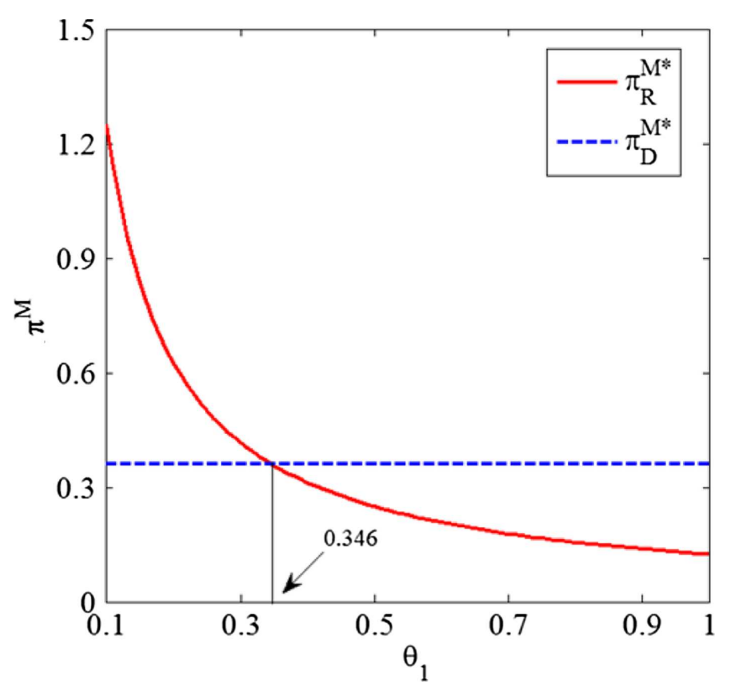

FiguRE 3. Manufacturer's profit changes with $\theta_{1}$.

Figures 2-4 illustrate the impact of $\theta_{1}$ on the two players' and the supply chain's profits, where $a=1, \beta=0.5$, $\lambda=0.5, \theta_{2}=0.5$ and $r_{f}=0.05$. According to Figures $2-4$, we have the following results: (i) in the retail channel, the retailer's profit increases with $\theta_{1}$ while manufacturer's and the supply chain's profits decrease with $\theta_{1}$; (ii) when $\theta_{1} \in(0,0.267]$, the retailer prefers the dual channels while the manufacturer and the supply chain prefer the single retail channel; when $\theta_{1} \in(0.267,0.346]$, two players and the supply chain prefer retail channel; when $\theta_{1} \in(0.346,0.351]$, the manufacturer prefers the dual channels while the retailer and the supply chain prefer the retail channel; when $\theta_{1} \in(0.351,1)$, the retailer prefers the retail channel while the manufacturer and the supply chain prefer the dual channels. 


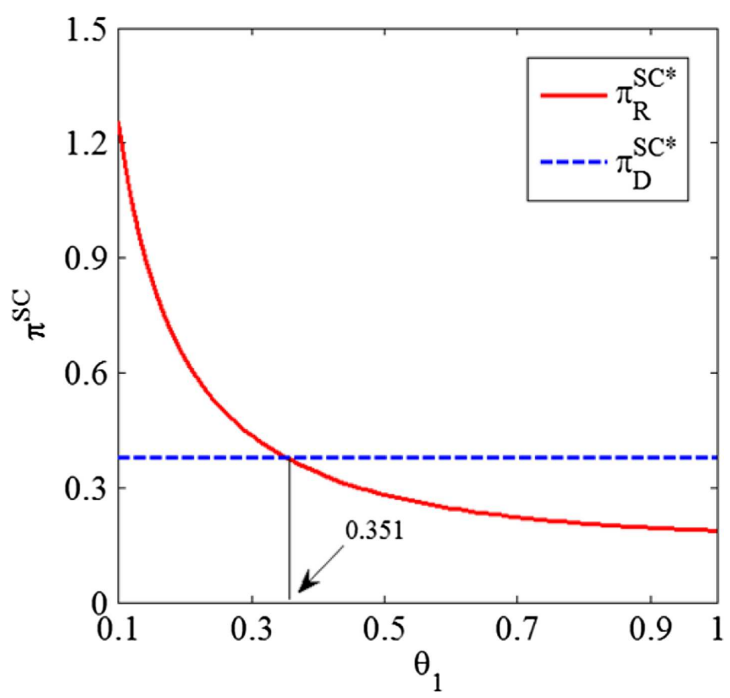

FiguRE 4. Supply chain's profit changes with $\theta_{1}$.

Figures 5-7 illustrate the impact of $\theta_{2}$ on the equilibrium profits, where $a=1, \beta=0.5, \lambda=0.5$ and $r_{f}=0.05$. As shown in Figures 5-7, we have the following results: (i) in the dual channels, the retailer's profit increases with $\theta_{2}$, but the manufacturer's and the supply chain's profits decrease with $\theta_{2}$; (ii) when $\theta_{1}$ is relatively low (e.g., $\theta_{1}=0.1$ ), the retailer always prefers the dual channels while the manufacturer and the supply chain prefer the single retail channel; (iii) when $\theta_{1}$ is medium (e.g., $\theta_{1}=0.3$ ), the players' channel preferences depends on $\theta_{2}$. If $\theta_{2} \in(0,0.563]$, the retailer prefers the retail channel but the manufacturer and the supply chain prefer the dual channels; if $\theta_{2} \in(0.563,0.602]$, the retailer and the supply chain prefer the retail channel but the manufacturer prefers the dual channels; if $\theta_{2} \in(0.602,0.863]$, the retailer, the manufacturer and the supply chain all prefer the retail channel; if $\theta_{2} \in(0.863,1]$, the retailer prefers the dual channels but the manufacturer and the supply chain prefer the retail channel; (iv) when $\theta_{1}$ is relatively high $\left(e . g ., \theta_{1}=0.6\right)$, the retailer always prefers the single retail channel while the manufacturer and the supply chain prefer the dual channels.

When the manufacturer's optimal channel choice is not consistent with that of the retailer, it may incur conflict between two players. Next, we develop a mechanism to solve this potential conflict. In terms of the channel preferences of the manufacturer, retailer and supply chain, according to Propositions 5.2 and 5.4, we observe three determinants: $\bar{\theta}_{1}, \hat{\theta}_{1}$ and $\theta_{1}^{*}$. It is difficult to make a theoretical comparison among $\bar{\theta}_{1}, \hat{\theta}_{1}$ and $\theta_{1}^{*}$. Therefore, we list all possible cases, which are shown in Table B.1 (see Appendix B). To solve the potential channel conflict, we consider a bilateral payment mechanism. When the manufacturer and the supply chain prefer dual channels, while the retailer prefers retail channel (e.g., (D, R, D, D) in Tab. B.1), then the manufacturer can transfer a certain fee $F$ to induce the retailer to allow his adding a new channel. In this case, the equilibrium channel structure is a dual-channel structure. When the manufacturer prefers dual channels, while the retailer and the supply chain prefer retail channel (e.g., (D, R, R, R) in Tab. B.1), then it is not worthwhile for the manufacturer to transfer a certain fee to induce the retailer to allow his adding a new channel. Therefore, the equilibrium channel structure is retail channel. Interestingly, in the case that the retailer and the supply chain prefer dual channels, while the manufacturer prefers retail channel (e.g., (R, D, D, D) in Tab. B.1), then the retailer can transfer a certain fee $G$ to induce the manufacturer to add a new channel. In this case, the equilibrium channel structure is a dual-channel structure. In addition, Table B.1 also shows that a bilateral payment mechanism can improve the efficiency of the supply chain and make both players better off. 

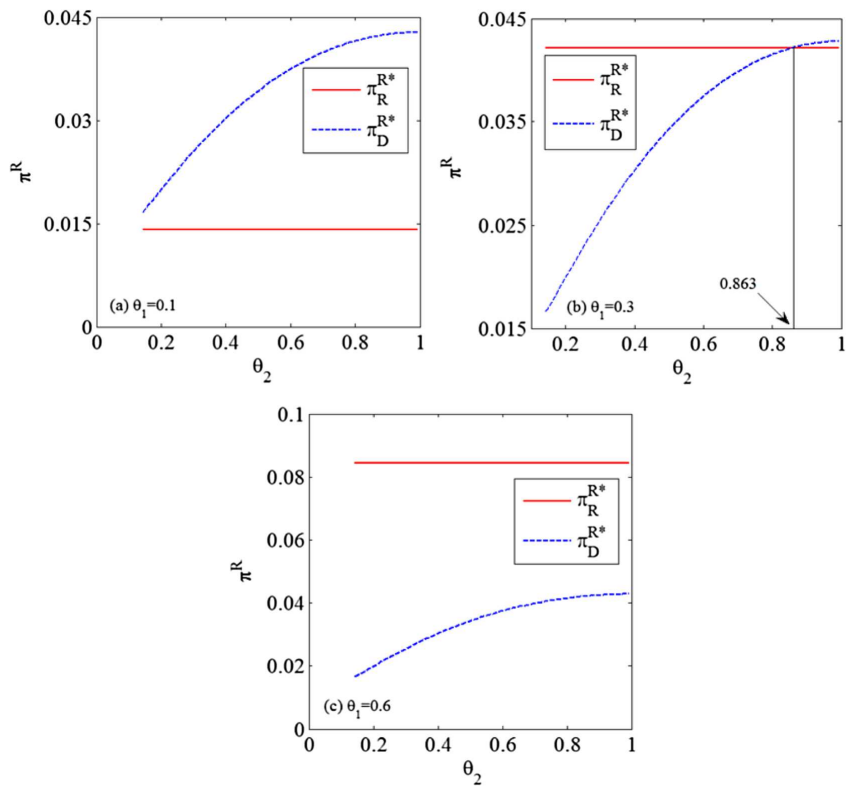

Figure 5 . The retailer's profit changes with $\theta_{2}$.
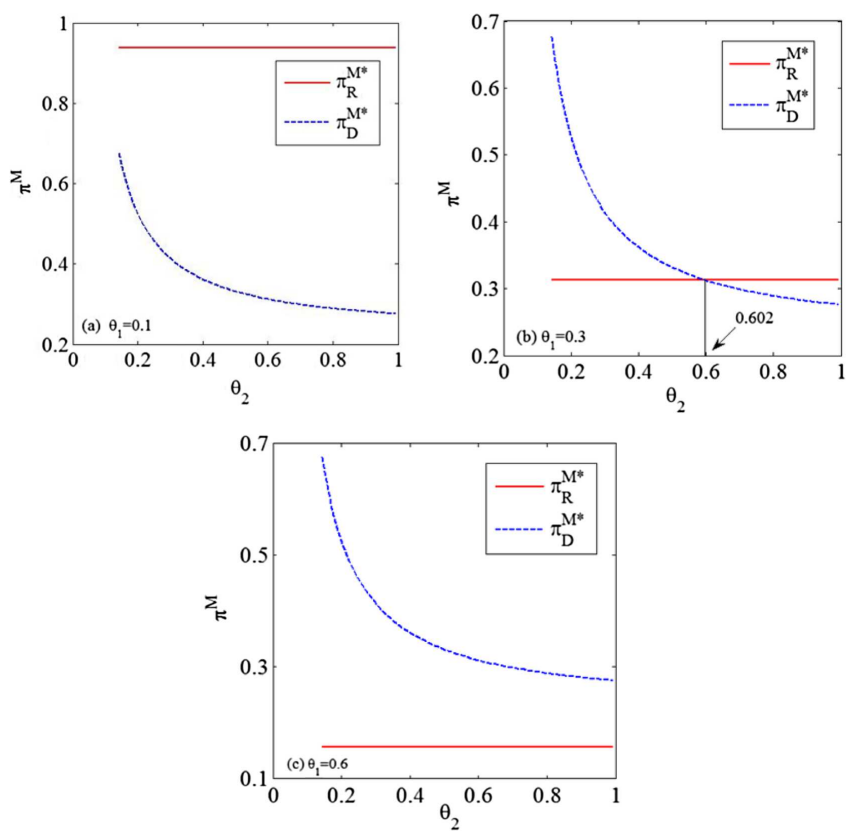

FIGURE 6 . The manufacturer's profit changes with $\theta_{2}$. 

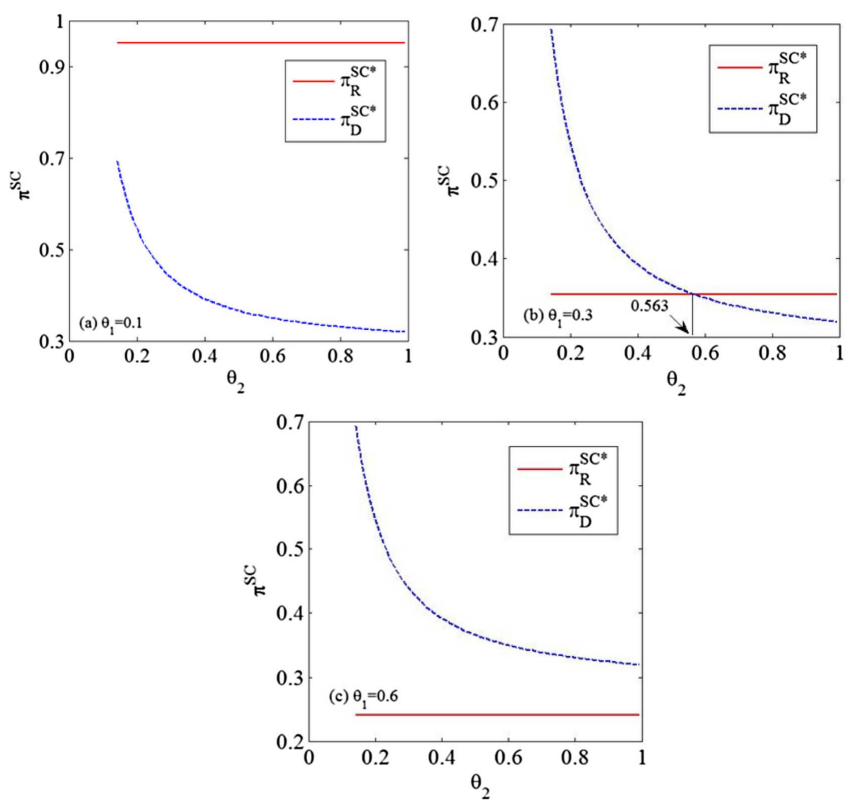

FiguRE 7 . The supply chain's profit changes with $\theta_{2}$.

\section{ExTENSION}

As shown in Section 4, the players' profits under dual channels are independent with $\theta_{1}$. Therefore, when making a comparison between dual channels and retail channel, the players' profits remain constant under dual channels while vary with $\theta_{1}$ under retail channel. In this section, we focus on a special case $\theta_{2}=\theta_{1}=\theta$. In this case, the players' profits under retail channel and dual channels are dependent on $\theta$. By making a comparison between these two channel structures, we have the following results.

Proposition 6.1. Suppose $\theta_{2}=\theta_{1}=\theta$, then

(i) If $\theta>\frac{\beta}{2-\beta}$, then $w_{D}^{*}>w_{R}^{*}$; if $\theta \leq \frac{\beta}{2-\beta}$, then $w_{D}^{*} \leq w_{R}^{*}$;

(ii) $q_{R}^{*} \geq q_{D}^{r *}$ and $q_{D}^{d *}+q_{D}^{r *} \geq q_{R}^{*}$;

(iii) $\pi_{D}^{R *}<\pi_{R}^{R *}$ and $\pi_{D}^{M *}>\pi_{R}^{M *}$.

From Proposition 6.1, when the retailer has the same bank loans ratio under two different channel structures, the manufacturer always prefers the dual channels while the retailer prefers the retail channel. As shown in Proposition 6.1, adding a direct channel will increase the total market demand but decrease the demand in the retail channel of dual channels. When $\theta$ exceeds a certain threshold, the wholesale price under dual channels is greater than that under retail channel, it is obvious that adding a direct channel benefits the manufacturer but hurts the retailer. However, when $\theta$ is relatively low, the manufacturer will announce a lower wholesale price in contrast to the retail channel. The positive effect of the increased total market demand dominates the negative effect of the decreased wholesale price under dual channels on the manufacturer's profit. Therefore, the manufacturer's profit under dual channels is greater than that under retail channel. From the retailer's perspective, the positive effect of the decreased wholesale price dominates the negative effect of the decreased market demand on the retailers profit. Therefore, the retailers profit under dual channels is lower than that under retail channel. 


\section{Conclusions and management insights}

In this paper, we consider the bargaining equilibrium in a two-echelon supply chain with a manufacturer and a capital constrained retailer, where the manufacturer considers adding a direct channel in competition with the traditional retail channel. Comparing with previous research, we incorporate equity financing into our model, which enables us to investigate the impact of bank loans ratio on the players' optimal decisions.

We also yield some useful results complement the existing literature. First, in the single retail channel a high bank loans ratio will benefit the retailer but hurt the manufacturer. In the dual channel, the manufacturer's profit decreases with the bank loans ratio. Second, adding a direct channel will benefit the manufacturer and supply chain when the bank loans ratio in the single retail channel is beyond a certain threshold. However, the retailer prefers the dual channels only and only if the bank loans ratio in the retail channel is below a certain threshold. Third, compared with the retail channel, a dual-channel structure can decrease the degree of the double marginalization.

Our study also leads to some managerial insights. First, from the manufacturer's perspective, he should add a new sales channel when the retailer's bank loans ratio in the retail channel is sufficiently large. In addition, the manufacturer and the retailer should try their best to increase bargaining powers and obtain greater profits. Second, it is wise for the manufacturer to encourage the retailer to borrow more from the external investors. Third, with the development of e-commerce, channel competition and conflict become inevitable. We show that a bilateral payment mechanism can improve the efficiency of the supply chain and achieve a win-win result.

The paper can be extended along the following possible directions. In this paper, we consider a deterministic demand model. However, the players may face an uncertain demand for some new products. Therefore, investigating the impact of the demand uncertainty on the channel selection is an interesting topic. Another possible extension is to consider other effective mechanisms such as revenue sharing contract to benefit both players.

Acknowledgements. The research is supported by the National Natural Science Foundation of China under Grant Nos. 71571065,71521061 and 71790593 .

\section{Appendix A. Proofs}

Proof of Lemma 4.1. According to Problem (4.1), $\pi_{R}^{R}$ is concave in $q_{R}$. Taking the first-order condition with respect to $q_{R}$, we have $q_{R}^{*}=\frac{a-\theta_{1} w_{R}\left(1+r_{f}\right)}{2}$. Given $q_{R}^{*}$, denote $\bar{\Phi}_{1}=\ln \Phi_{1}=\beta \ln \pi_{R}^{M}+(1-\beta) \ln \pi_{R}^{R}$. Let $\frac{\partial \bar{\Phi}_{1}}{\partial w_{R}}=0$, then $w_{R}^{*}=\frac{a \beta}{2 \theta_{1}\left(1+r_{f}\right)}$. Since $\left.\frac{\partial^{2} \bar{\Phi}_{1}}{\partial\left(w_{R}\right)^{2}}\right|_{w_{R}=w_{R}^{*}}<0$, we conclude that $w_{R}^{*}$ is the unique wholesale price that maximizes $\Phi_{1}$ and $\bar{\Phi}_{1}$. Further, we derive $q_{R}^{*}, p_{R}^{*}, \pi_{R}^{R *}$ and $\pi_{R}^{M *}$.

Proof of Lemma 4.2. According to Problem (4.4), $\pi_{R}^{D}$ is concave in $q_{D}^{r}$. Taking the first-order condition with respect to $q_{D}^{r}$, we have $q_{D}^{r *}=\frac{a-\lambda q_{D}^{d}-\theta_{2} w_{D}\left(1+r_{f}\right)}{2}$. Given $q_{D}^{r *}$, let $\bar{\Phi}_{2}=\ln \Phi_{2}=\beta \ln \left(\pi_{D}^{M}-\bar{\pi}_{D}^{M}\right)+(1-\beta) \ln \pi_{D}^{R}$. Differentiating $\bar{\Phi}_{2}$ with respect to $w_{D}$, we have $w_{D}^{*}\left(q_{D}^{r}\right)=\frac{a \beta-\beta \lambda q_{D}^{d}+2 \lambda \theta_{2} q_{D}^{d}-\beta \lambda \theta_{2} q_{D}^{d}}{2 \theta_{2}\left(1+r_{f}\right)}$. Further, $\left.\frac{\partial^{2} \bar{\Phi}_{2}}{\partial\left(w_{D}\right)^{2}}\right|_{w_{D}=w_{D}^{*}}<0$. then $w_{D}^{*}$ is the unique wholesale price that maximizes $\Phi_{2}$ and $\bar{\Phi}_{2}$. Given $w_{D}^{*}$ and $\frac{\partial \pi_{D}^{M}}{\partial q_{D}^{d}}=0$, then $q_{D}^{d *}=\frac{a\left(4 \theta_{2}-2 \beta \lambda+\beta^{2} \lambda-2 \beta \lambda \theta_{2}+\beta^{2} \lambda \theta_{2}\right)}{\beta^{2} \lambda^{2} \theta_{2}{ }^{2}+2 \beta^{2} \lambda^{2} \theta_{2}+\beta^{2} \lambda^{2}-2 \beta \lambda^{2} \theta_{2}^{2}-4 \beta \lambda^{2} \theta_{2}-2 \beta \lambda^{2}+8 \theta_{2}}$. Further, we derive $w_{D}^{*}, q_{r}^{r *}, p_{D}^{r *}, \pi_{D}^{M *}$ and $\pi_{D}^{R *}$.

To ensure $w_{D}^{*}>0, q_{D}^{d *}>0$ and $q_{D}^{r *}>0$, we have $\theta_{2}>\frac{\beta \lambda(2-\beta)}{\lambda \beta^{2}-2 \lambda \beta+4}$. Since $\frac{\beta \lambda(2-\beta)}{\lambda \beta^{2}-2 \lambda \beta+4}$ increases with $\beta$, for $\beta \in[0,1]$, we have $\theta_{2}>\left.\frac{\beta \lambda(2-\beta)}{\lambda \beta^{2}-2 \lambda \beta+4}\right|_{\beta=1}=\frac{\lambda}{4-\lambda}$. Therefore, $w_{D}^{*}>0, q_{D}^{d *}>0$ and $q_{D}^{r *}>0$ if $\theta_{2}>\frac{\lambda}{4-\lambda}$ for $\beta \in[0,1]$. 


\section{Proof of Proposition 4.3.}

(i) From Lemma 4.2, $\frac{\partial w_{D}^{*}}{\partial \beta}=\frac{2 a\left(\lambda+\lambda \theta_{2}-2\right) m_{1}}{\left(\beta^{2} \lambda^{2} \theta_{2}^{2}+2 \beta^{2} \lambda^{2} \theta_{2}+\beta^{2} \lambda^{2}-2 \beta \lambda^{2} \theta_{2}^{2}-4 \beta \lambda^{2} \theta_{2}-2 \beta \lambda^{2}+8 \theta_{2}\right)^{2}\left(1+r_{f}\right)}$, where $m_{1}=\beta^{2} \lambda^{2} \theta_{2}{ }^{2}+$ $2 \beta^{2} \lambda^{2} \theta_{2}+\beta^{2} \lambda^{2}-4 \beta \lambda^{2} \theta_{2}{ }^{2}-4 \beta \lambda^{2} \theta_{2}+4 \beta^{2} \theta_{2}{ }^{2}-8 \theta_{2}+4 \lambda^{2} \theta_{2}$. Since $m_{1}$ is convex in $\theta_{2}, m_{1}<0$ if $\theta_{2}=\frac{\lambda}{4-\lambda}$, and $m_{1}<0$ if $\theta_{2}=1$, we easily have $m_{1}<0$, i.e., $\frac{\partial w_{D}^{*}}{\partial \beta}>0$.

Further, we have $\frac{\partial q_{D}^{d *}}{\partial \beta}=-\frac{8 a \lambda \theta_{2}\left(1+\theta_{2}\right)\left(\lambda+\lambda \theta_{2}-2\right)(\beta-1)}{\left(\beta^{2} \lambda^{2} \theta_{2}^{2}+2 \beta^{2} \lambda^{2} \theta_{2}+\beta^{2} \lambda^{2}-2 \beta \lambda^{2} \theta_{2}^{2}-4 \beta \lambda^{2} \theta_{2}-2 \beta \lambda^{2}+8 \theta_{2}\right)^{2}}$.

From Lemma 4.2, $\frac{\partial q_{D}^{r * *}}{\partial \beta}=\frac{a \theta_{2}\left(2-\lambda-\lambda \theta_{2}\right) m_{2}}{\left(\beta^{2} \lambda^{2} \theta_{2}^{2}+2 \beta^{2} \lambda^{2} \theta_{2}+\beta^{2} \lambda^{2}-2 \beta \lambda^{2} \theta_{2}^{2}-4 \beta \lambda^{2} \theta_{2}-2 \beta \lambda^{2}+8 \theta_{2}\right)^{2}}$, where $m_{2}=\beta^{2} \lambda^{2} \theta_{2}^{2}+2 \beta^{2} \lambda^{2} \theta_{2}+$ $\beta^{2} \lambda^{2}-4 \beta \lambda^{2} \theta_{2}^{2}-8 \beta \lambda^{2} \theta_{2}-4 \beta \lambda^{2}+4 \beta^{2} \theta_{2}^{2}-8 \theta_{2}+8 \lambda^{2} \theta_{2}+4 \lambda^{2}$. We show that $m_{2}(\beta)$ decreases with $\beta$ and $m_{2}(1)<0$. When $\beta=0$, then $m_{2}(0)=4 \lambda^{2} \theta_{2}^{2}+8 \lambda^{2} \theta_{2}+4 \lambda^{2}-8 \theta_{2}$. We further find that $m_{2}(0)$ is convex in $\theta_{2}$, and $\theta_{2}=\frac{1-\lambda^{2}}{\lambda^{2}}$ minimizes $m_{2}(0)$.

When $\lambda<\frac{\sqrt{2}}{2}$, then $\frac{1-\lambda^{2}}{\lambda^{2}}>1$. Therefore, $m_{2}(0)$ decreases with $\theta_{2}$ for $\theta_{2} \in\left(\frac{\lambda}{4-\lambda}, 1\right],\left.m_{2}(0)\right|_{\theta_{2}=\frac{\lambda}{4-\lambda}}=\frac{8 \lambda(9 \lambda-4)}{(4-\lambda)^{2}}$ and $\left.m_{2}(0)\right|_{\theta_{2}=1}=16 \lambda^{2}-8<0$. If $\lambda<\frac{4}{9}$, then $\left.m_{2}(0)\right|_{\theta_{2}=\frac{\lambda}{4-\lambda}}<0$; if $\frac{4}{9} \leq \lambda<\frac{\sqrt{2}}{2}$, then $\left.m_{2}(0)\right|_{\theta_{2}=\frac{\lambda}{4-\lambda}} \geq 0$. Therefore, when $\lambda<\frac{4}{9}$, then $m_{2}(0)<0$; when $\frac{4}{9} \leq \lambda<\frac{\sqrt{2}}{2}$, there exists a unique $\bar{\theta}$ such that $m_{2}(0) \geq 0$ if $\theta_{2} \leq \bar{\theta}$, and $m_{2}(0)<0$ if $\theta_{2}>\bar{\theta}$.

When $\lambda \geq \frac{\sqrt{2}}{2}$, then $\frac{\lambda}{4-\lambda}<\frac{1-\lambda^{2}}{\lambda^{2}} \leq 1$, i.e., $m_{2}(0)$ is convex in $\theta_{2}$. Since $\left.m_{2}(0)\right|_{\theta_{2}=\frac{1-\lambda^{2}}{\lambda^{2}}}=\frac{4\left(2 \lambda^{2}-1\right)}{\lambda^{2}}>0$, we easily have $m_{2}(0)>0$.

To summarize, when $\lambda<\frac{4}{9}$ or when $\frac{4}{9}<\lambda<\frac{\sqrt{2}}{2}$ and $\theta_{2}>\bar{\theta}$, then $\frac{\partial q_{D}^{r *}}{\partial \beta}<0$; when $\frac{4}{9} \leq \lambda<\frac{\sqrt{2}}{2}$ and $\theta_{2} \leq \bar{\theta}$ or when $\lambda \geq \frac{\sqrt{2}}{2}$, then there exists a unique $\beta_{1}$ such that $\frac{\partial q_{D}^{r *}}{\partial \beta} \geq 0$ if $\beta \leq \beta_{1}$, and $\frac{\partial q_{D}^{r *}}{\partial \beta}<0$ if $\beta>\beta_{1}$.

(ii) Proof of (ii) is similar to that of (i), and hence is omitted.

Proof of Proposition 5.1.

(i) From Proposition 4.3, we have $w_{R}^{*}-w_{D}^{*}$ increases with $\theta_{2}$.

When $\theta_{2}=\frac{\lambda}{4-\lambda}$, then

$$
\begin{aligned}
& 8\left(4 \beta \lambda-16 \beta \theta_{1}-\beta \lambda^{2}-4 \lambda^{2} \theta_{1}+\lambda^{3} \theta_{1}-4 \beta^{2} \lambda^{2}+2 \beta^{3} \lambda^{2}-4 \beta^{2} \lambda^{2} \theta_{2}+\right. \\
& w_{R}^{*}-w_{D}^{*}=\frac{\left.\beta^{2} \lambda^{3} \theta_{2}+16 \beta \lambda \theta_{1}+5 \beta \lambda^{2} \theta_{1}-2 \beta \lambda^{3} \theta_{1}\right)}{(4-\lambda)^{2}}
\end{aligned}
$$

If $\theta_{1} \rightarrow 0$, then $\left.\left(w_{R}^{*}-w_{D}^{*}\right)\right|_{\theta_{2}=\frac{\lambda}{4-\lambda}}>0$

If $\theta_{1}=1$, then $\left.\left(w_{R}^{*}-w_{D}^{*}\right)\right|_{\theta_{2}=\frac{\lambda}{4-\lambda}}<0$. Therefore, there exists a unique $\theta_{11}$ such that $\left.\left(w_{R}^{*}-w_{D}^{*}\right)\right|_{\theta_{2}=\frac{\lambda}{4-\lambda}}>0$ if $\theta_{1}<\theta_{11}$, and $\left.\left(w_{R}^{*}-w_{D}^{*}\right)\right|_{\theta_{2}=\frac{\lambda}{4-\lambda}} \leq 0$ if $\theta_{1} \geq \theta_{11}$, where $\theta_{11}=\frac{\beta \lambda\left(2 \lambda \beta^{2}-4 \lambda \beta-\lambda+4\right)}{(4-\lambda)\left(\beta^{2} \lambda^{2}-2 \beta \lambda^{2}-3 \beta \lambda+4 \beta+\lambda^{2}\right)}$.

When $\theta_{2}=1$, then $w_{R}^{*}-w_{D}^{*}=\frac{a\left(8 \beta-8 \beta \theta_{1}-8 \lambda \theta_{1}-8 \beta^{2} \lambda^{2}+4 \beta^{3} \lambda^{2}-4 \beta^{2} \lambda^{2} \theta_{1}+8 \beta \lambda \theta_{1}+8 \beta \lambda^{2} \theta_{1}\right)}{2 \theta_{1}\left(4 \beta^{2} \lambda^{2}-8 \beta \lambda^{2}+8\right)\left(1+r_{f}\right)}$.

If $\theta_{1} \rightarrow 0$, then $\left.\left(w_{R}^{*}-w_{D}^{*}\right)\right|_{\theta_{2}=1}>0$;

If $\theta_{1}=1$, then $\left.\left(w_{R}^{*}-w_{D}^{*}\right)\right|_{\theta_{2}=1}<0$. Therefore, there exists a unique $\theta_{12}$ such that $\left.\left(w_{R}^{*}-w_{D}^{*}\right)\right|_{\theta_{2}=2}>0$ if $\theta_{1}<\theta_{12}$, and $\left.\left(w_{R}^{*}-w_{D}^{*}\right)\right|_{\theta_{2}=1} \leq 0$ if $\theta_{1} \geq \theta_{12}$, where $\theta_{12}=\frac{\beta\left(2 \lambda^{2} \beta^{2}-2 \lambda^{2} \beta+2\right)}{\beta^{2} \lambda^{2}-2 \beta \lambda^{2}-2 \beta \lambda+2 \beta+2 \lambda}$ and $\theta_{11}<\theta_{12}$.

To sum up, we have the following results:

When $\theta_{1} \leq \theta_{11}$, then $w_{R}^{*}-w_{D}^{*} \geq 0$;

When $\theta_{11}<\theta_{1} \leq \theta_{12}$, then there exists a unique $\theta_{21}$ such that if $\theta_{2} \geq \theta_{21}$, then $w_{R}^{*}-w_{D}^{*} \geq 0$; if $\theta_{2}<\theta_{21}$, then $w_{R}^{*}-w_{D}^{*}<0$;

When $\theta_{1}>\theta_{12}$, then $w_{R}^{*}-w_{D}^{*}<0$.

(ii) Since $q_{R}^{*}-q_{D}^{r *}=\frac{a \lambda\left(1+\theta_{2}\right)(2-\beta)\left(4 \theta_{2}-2 \beta \lambda+\beta^{2} \lambda-2 \beta \lambda \theta_{2}+\beta^{2} \lambda \theta_{2}\right)}{4\left(\beta^{2} \lambda^{2} \theta_{2}^{2}+2 \beta^{2} \lambda^{2} \theta_{2}+\beta^{2} \lambda^{2}-2 \beta \lambda^{2} \theta_{2}^{2}-4 \beta \lambda^{2} \theta_{2}-2 \beta \lambda^{2}+8 \theta_{2}\right)}$, then $q_{R}^{*}>q_{D}^{r *}$.

(iii) Since $q_{D}^{d *}-q_{D}^{r *}=\frac{{ }^{2}}{\beta^{2} \lambda^{2} \theta_{2}{ }^{2}+2 \beta^{2} \lambda^{2} \theta_{2}+\beta^{2} \lambda^{2}-2 \beta \lambda^{2} \theta_{2}{ }^{2}-4 \beta \lambda^{2} \theta_{2}-2 \beta \lambda^{2}+8 \theta_{2}}$, where $y_{1}=2 \beta \theta_{2}-2 \beta \lambda+2 \lambda \theta_{2}+\beta^{2} \lambda+$ $2 \lambda \theta_{2}{ }^{2}-3 \beta \lambda \theta_{2}-\beta \lambda \theta_{2}{ }^{2}+\beta^{2} \lambda \theta_{2}$. We find that $y_{1}$ increases with $\theta_{2}$. When $\theta_{2}=1$, then $y_{1}>0$; when 
$\theta_{2}=\frac{\lambda}{4-\lambda}$, then $y_{1}=\frac{2 \lambda\left(4 \lambda+\beta \lambda-2 \beta^{2} \lambda+8 \beta^{2}-12 \beta\right)}{(\lambda-4)^{2}}$. We show that $y_{2}(\lambda)=4 \lambda+\beta \lambda-2 \beta^{2} \lambda+8 \beta^{2}-12 \beta$ increases with $\lambda$ and $y_{2}(0)<0$. Since $y_{2}(1)<0$ if $\beta>\frac{1}{2}$, and $y_{2}(1) \geq 0$ if $\beta \leq \frac{1}{2}$, there exists a unique $\lambda_{1}$ such that $y_{2}(\lambda) \geq 0$ if $\lambda \geq \lambda_{1}$, and $y_{2}(\lambda)<0$ if $\lambda<\lambda_{1}$.

To sum up, we have the following results: When $\beta \leq \frac{1}{2}$ and $\lambda \geq \lambda_{1}$, then $y_{1} \geq 0$, i.e., $q_{D}^{d *} \geq q_{D}^{r *}$;

When $\beta \leq \frac{1}{2}$ and $\lambda<\lambda_{1}$ or when $\beta>\frac{1}{2}$, then there exists a unique $\theta_{22}$ such that $q_{D}^{d *}>q_{D}^{r *}$ if $\theta_{2}>\theta_{22}$, and $q_{D}^{d *} \leq q_{D}^{r *}$ if $\theta_{2} \leq \theta_{22}$

(iv) Since $q_{D}^{d *}+q_{D}^{r *}-q_{R}^{*}=\frac{a\left(\beta \lambda-2 \lambda-2 \lambda \theta_{2}+\beta \lambda \theta_{2}+4\right)\left(4 \theta_{2}-2 \beta \lambda+\beta^{2} \lambda-2 \beta \lambda \theta_{2}+\beta^{2} \lambda \theta_{2}\right)}{4\left(\beta^{2} \lambda^{2} \theta_{2}^{2}+2 \beta^{2} \lambda^{2} \theta_{2}+\beta^{2} \lambda^{2}-2 \beta \lambda^{2} \theta_{2}^{2}-4 \beta \lambda^{2} \theta_{2}-2 \beta \lambda^{2}+8 \theta_{2}\right)}$, then $q_{D}^{d *}+q_{D}^{r *}>q_{R}^{*}$.

Proof of Proposition 5.2.

(i) $\frac{\partial \pi_{R}^{M *}}{\partial \theta_{1}}=-\frac{a^{2} \beta(2-\beta)}{8 \theta_{1}^{2}}<0$ and $\frac{\partial \pi_{R}^{R *}}{\partial \theta_{1}}=\frac{a^{2}(2-\beta)^{2}}{16}>0$;

(ii) First, since $\frac{\partial\left(\pi_{D}^{M *}-\pi_{R}^{M *}\right)}{\partial \theta_{1}}=\frac{a^{2} \beta(2-\beta)}{8 \theta_{1}{ }^{2}}>0,\left.\left(\pi_{D}^{M *}-\pi_{R}^{M *}\right)\right|_{\theta_{1} \rightarrow 0}<0$ and $\left.\left(\pi_{D}^{M *}-\pi_{R}^{M *}\right)\right|_{\theta_{1}=1}>0$, then there exists a unique $\bar{\theta}_{1} \in(0,1]$ such that $\pi_{D}^{M *} \geq \pi_{R}^{M *}$ if $\theta_{1} \geq \bar{\theta}_{1}$, and $\pi_{D}^{M *}<\pi_{R}^{M *}$ if $\theta_{1}<\bar{\theta}_{1}$.

Second, since $\frac{\partial\left(\pi_{D}^{R *}-\pi_{R}^{R *}\right)}{\partial \theta_{1}}=-\frac{a^{2}(2-\beta)}{16}<0,\left.\left(\pi_{D}^{R *}-\pi_{R}^{R *}\right)\right|_{\theta_{1} \rightarrow 0}>0$ and $\left.\left(\pi_{D}^{R *}-\pi_{R}^{R *}\right)\right|_{\theta_{1}=1}<0$, then there exists a unique $\hat{\theta}_{1}$ such that $\pi_{D}^{R *}>\pi_{R}^{R *}$ if $\theta_{1}<\hat{\theta}_{1}$, and $\pi_{D}^{R *} \geq \pi_{R}^{R *}$ if $\theta_{1} \leq \hat{\theta}_{1}$.

Proof of Proposition 5.3.

(i) $\frac{\partial \pi_{D}^{M *}}{\partial \theta_{2}}=-\frac{a^{2} \beta(2-\beta)\left(2-\lambda+\lambda \theta_{2}\right)\left(\beta^{2} \lambda^{2} \theta_{2}-2 \beta \lambda^{2} \theta_{2}+2 \lambda \theta_{2}+\beta^{2} \lambda^{2}-2 \beta \lambda^{2}-2 \lambda+4\right)}{\left(\beta^{2} \lambda^{2} \theta_{2}^{2}+2 \beta^{2} \lambda^{2} \theta_{2}+\beta^{2} \lambda^{2}-2 \beta \lambda^{2} \theta_{2}^{2}-4 \beta \lambda^{2} \theta_{2}-2 \beta \lambda^{2}+8 \theta_{2}\right)^{2}}<0$.

(ii) Since $\pi_{R}^{M *}$ is independent of $\theta_{2}$, then $\pi_{D}^{M *}-\pi_{R}^{M *}$ decreases with $\theta_{2}$.

When $\theta_{2}=\frac{\lambda}{4-\lambda}$, then

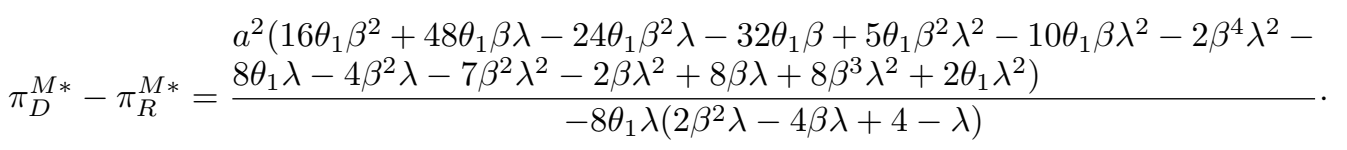

Since $\pi_{D}^{M *}$ is independent of $\theta_{1}$ and $\pi_{R}^{M *}$ equals $\frac{a^{2} \beta(2-\beta)}{8 \theta_{1}}$. Then we easily obtain that $\pi_{D}^{M *}-\pi_{R}^{M *}$ increases with $\theta_{1}$. Further, $\left.\left(\pi_{D}^{M *}-\pi_{R}^{M *}\right)\right|_{\theta_{2}=\frac{\lambda}{4-\lambda}}<0$ if $\theta_{1} \rightarrow 0$, and $\left.\left(\pi_{D}^{M *}-\pi_{R}^{M *}\right)\right|_{\theta_{2}=\frac{\lambda}{4-\lambda}}>0$ if $\theta_{1}=1$. Therefore, there exists a unique $\theta_{13}$ such that $\left.\left(\pi_{D}^{M *}-\pi_{R}^{M *}\right)\right|_{\theta_{2}=\frac{\lambda}{4-\lambda}} \leq 0$ if $\theta_{1} \leq \theta_{13}$, and $\left.\left(\pi_{D}^{M *}-\pi_{R}^{M *}\right)\right|_{\theta_{2}=\frac{\lambda}{4-\lambda}}>0$ if $\theta_{1}>\theta_{13}$, where $\theta_{13}=\frac{\beta \lambda(2-\beta)\left(2 \beta^{2} \lambda-4 \beta \lambda+4-\lambda\right)}{\left(5 \beta^{2} \lambda-10 \beta \lambda+2 \lambda+8 \beta-4 \beta^{2}\right)(4-\lambda)}$.

When $\theta_{2}=1$, then $\pi_{D}^{M *}-\pi_{R}^{M *}=\frac{a^{2}\left(4 \theta_{1}-8 \theta_{1} \beta \lambda+4 \theta_{1} \beta^{2} \lambda-2 \theta_{1} \beta^{2}+4 \theta_{1} \beta+\beta^{4} \lambda a^{2}-4 \beta^{3} \lambda a^{2}+2 \beta^{2}+4 \beta^{2} \lambda^{2}-4 \beta\right)}{8 \theta_{1}\left(\beta^{2} \lambda^{2}-2 \beta \lambda^{2}+2\right)}$. We observe that $\left.\left(\pi_{D}^{M *}-\pi_{R}^{M *}\right)\right|_{\theta_{2}=1}$ increases with $\theta_{1}$. If $\theta_{1} \rightarrow 0$, then $\left.\left(\pi_{D}^{M *}-\pi_{R}^{M *}\right)\right|_{\theta_{2}=1}<0$. If $\theta_{1}=1$, then $\left.\left(\pi_{D}^{M *}-\pi_{R}^{M *}\right)\right|_{\theta_{2}=1}>0$. Therefore, there exists a unique $\theta_{14}$ such that $\left.\left(\pi_{D}^{M *}-\pi_{R}^{M *}\right)\right|_{\theta_{2}=1} \geq 0$ if $\theta_{1} \geq \theta_{14}$, and $\left.\left(\pi_{D}^{M *}-\pi_{R}^{M *}\right)\right|_{\theta_{2}=1}<0$ if $\theta_{1}<\theta_{14}$, where $\theta_{14}=-\frac{\beta\left(4 \beta \lambda^{2}+\beta^{3} \lambda a^{2}-4 \beta^{2} \lambda a^{2}+2 \beta-4\right)}{2\left(2+2 \beta^{2} \lambda-\beta^{2}+2 \beta-4 \beta \lambda\right)}>\theta_{13}$.

To sum up, we have the following results: When $\theta_{1} \leq \theta_{13}$, then $\pi_{D}^{M *} \leq \pi_{R}^{M *}$; When $\theta_{13}<\theta_{1}<\theta_{14}$, then there exists a unique $\theta_{23}$ such that $\pi_{D}^{M *} \geq \pi_{R}^{M *}$ if $\theta_{2} \leq \theta_{23}$, and $\pi_{D}^{M *}<\pi_{R}^{M *}$ if $\theta_{2}>\theta_{23}$; When $\theta_{1} \geq \theta_{14}$, then $\pi_{D}^{M *} \geq \pi_{R}^{M *}$

Proof of Proposition 5.4. In the case of $\beta=1$, according to Lemma 4.1, we have $\frac{\partial\left(\pi_{D}^{S C *}-\pi_{R}^{S C *}\right)}{\partial \theta_{1}}>0$. Let $\pi_{D}^{S C *}-$ $\pi_{R}^{S C *} \geq 0$, we have $\theta_{1} \geq \theta_{1}^{*}$, where $\theta_{1}^{*}$ holds the equation $\lambda^{4} \theta_{2}{ }^{4} \theta_{1}{ }^{2}+2 \lambda^{4} \theta_{2}{ }^{4}+4 \lambda^{4} \theta_{2}{ }^{3} \theta_{1}{ }^{2}+8 \lambda^{4} \theta_{2}{ }^{3}+6 \lambda^{4} \theta_{2}{ }^{2} \theta_{1}{ }^{2}+$ $12 \lambda^{4} \theta_{2}{ }^{2}+4 \lambda^{4} \theta_{2} \theta_{1}{ }^{2}+8 \lambda^{4} \theta_{2}+\lambda^{4} \theta_{1}{ }^{2}+2 \lambda^{4}-16 \lambda^{3} \theta_{2}{ }^{3} \theta_{1}-48 \lambda^{3} \theta_{2}{ }^{2} \theta_{1}-48 \lambda^{3} \theta_{2} \theta_{1}-16 \lambda^{3} \theta_{1}-16 \lambda^{2} \theta_{2}{ }^{5} \theta_{1}-32 \lambda^{2} \theta_{2}{ }^{4} \theta_{1}-$ $16 \lambda^{2} \theta_{2}{ }^{3} \theta_{1}{ }^{2}+16 \lambda^{2} \theta_{2}{ }^{3} \theta_{1}-32 \lambda^{2} \theta_{2}{ }^{3}-32 \lambda^{2} \theta_{2}{ }^{2} \theta_{1}{ }^{2}+80 \lambda^{2} \theta_{2}{ }^{2} \theta_{1}-64 \lambda^{2} \theta_{2}{ }^{2}-16 \lambda^{2} \theta_{2} \theta_{1}{ }^{2}+64 \lambda^{2} \theta_{2} \theta_{1}-32 \lambda^{2} \theta_{2}+16 \lambda^{2} \theta_{1}+$ $64 \lambda \theta_{2}{ }^{4} \theta_{1}+64 \lambda \theta_{2}{ }^{3} \theta_{1}+128 \lambda \theta_{2}{ }^{2} \theta_{1}+128 \lambda \theta_{2} \theta_{1}-64 \theta_{2}{ }^{3} \theta_{1}+64 \theta_{2}{ }^{2} \theta_{1}{ }^{2}-256 \theta_{2}{ }^{2} \theta_{1}+128 \theta_{2}{ }^{2}-128 \theta_{2} \theta_{1}=0$. 


\section{Proof of Proposition 6.1.}

(i) According to Lemmas 4.1 and 4.2, we have $w_{D}^{*}-w_{R}^{*}=\frac{-\lambda(\beta-2 \theta+\beta \theta) q_{D}^{d *}}{2 \theta\left(1+r_{f}\right)}$. Therefore, when $\theta>\frac{\beta}{2-\beta}$, then $w_{D}^{*}>w_{R}^{*} ;$ when $\theta \leq \frac{\beta}{2-\beta}$, then $w_{D}^{*} \leq w_{R}^{*}$

(ii) Since $q_{R}^{*}-q_{D}^{r *}=\frac{a \lambda(1+\theta)(2-\beta)\left(4 \theta-2 \beta \lambda+\beta^{2} \lambda-2 \beta \lambda \theta+\beta^{2} \lambda \theta\right)}{4\left(\beta^{2} \lambda^{2} \theta^{2}+2 \beta^{2} \lambda^{2} \theta+\beta^{2} \lambda^{2}-2 \beta \lambda^{2} \theta^{2}-4 \beta \lambda^{2} \theta-2 \beta \lambda^{2}+8 \theta\right)}$, then $q_{R}^{*}>q_{D}^{r *}$.

Further, since $q_{D}^{d *}+q_{D}^{r *}>q_{R}^{*}=\frac{a(\beta \lambda-2 \lambda-2 \lambda \theta+\beta \lambda \theta+4)\left(4 \theta-2 \beta \lambda+\beta^{2} \lambda-2 \beta \lambda \theta+\beta^{2} \lambda \theta\right)}{4\left(\beta^{2} \lambda^{2} \theta^{2}+2 \beta^{2} \lambda^{2} \theta+\beta^{2} \lambda^{2}-2 \beta \lambda^{2} \theta^{2}-4 \beta \lambda^{2} \theta-2 \beta \lambda^{2}+8 \theta\right)}$, then $q_{D}^{d *}+q_{D}^{r *}>q_{R}^{*}$.

(iii) First, $\pi_{D}^{R *}-\pi_{R}^{R *}=\frac{-\lambda \theta a^{2}(\beta-2)^{2}(1+\theta) m_{1} q_{D}^{d *}}{4\left(\beta^{2} \lambda^{2} \theta^{2}+2 \beta^{2} \lambda^{2} \theta+\beta^{2} \lambda^{2}-2 \beta \lambda^{2} \theta^{2}-4 \beta \lambda^{2} \theta-2 \beta \lambda^{2}+8 \theta\right)}$, where $m_{1}=\beta^{2} \lambda^{2} \theta^{2}+2 \beta^{2} \lambda^{2} \theta+\beta^{2} \lambda^{2}-$ $2 \beta \lambda^{2} \theta^{2}-4 \beta \lambda^{2} \theta-2 \beta \lambda^{2}-4 \theta^{2} \lambda-4 \lambda \theta+16 \theta$. Since $m_{1}>0$, then $\pi_{D}^{R *}<\pi_{R}^{R *}$.

Second, $\pi_{D}^{M *}-\pi_{R}^{M *}=\frac{a^{2}\left(4 \theta-2 \beta \lambda+\beta^{2} \lambda-2 \beta \lambda \theta+\beta^{2} \lambda \theta\right)^{2}}{8 \theta\left(\beta^{2} \lambda^{2} \theta^{2}+2 \beta^{2} \lambda^{2} \theta+\beta^{2} \lambda^{2}-2 \beta \lambda^{2} \theta^{2}-4 \beta \lambda^{2} \theta-2 \beta \lambda^{2}+8 \theta\right)}>0$.

\section{Appendix B. TABLes}

TABLE B.1. Channel preference and equilibrium channel structure.

\begin{tabular}{|c|c|c|c|}
\hline \multicolumn{4}{|c|}{$(\mathrm{MF}, \mathrm{RF}, \mathrm{SCF}, \mathrm{EC})$} \\
\hline \multirow[t]{3}{*}{$\hat{\theta_{1}} \leq \overline{\theta_{1}}$} & $\theta_{1}^{*} \leq \hat{\theta_{1}}$ & $\begin{array}{l}\theta_{1} \leq \theta_{1}^{*} \\
\theta_{1}^{*}<\theta_{1} \leq \hat{\theta}_{1} \\
\hat{\theta}_{1}<\theta_{1} \leq \bar{\theta}_{1} \\
\theta_{1}>\bar{\theta}_{1}\end{array}$ & $\begin{array}{l}(\mathrm{R}, \mathrm{D}, \mathrm{R}, \mathrm{R}) \\
(\mathrm{R}, \mathrm{D}, \mathrm{D}, \mathrm{D}), G=\left[\pi_{R}^{M *}-\pi_{D}^{M *}, \pi_{D}^{R *}-\pi_{R}^{R *}\right] \\
(\mathrm{R}, \mathrm{R}, \mathrm{D}, \mathrm{NA}) \\
(\mathrm{D}, \mathrm{R}, \mathrm{D}, \mathrm{D}), F=\left[\pi_{R}^{R *}-\pi_{D}^{R *}, \pi_{D}^{M *}-\pi_{R}^{M *}\right]\end{array}$ \\
\hline & $\hat{\theta}_{1}<\theta_{1}^{*} \leq \overline{\theta_{1}}$ & $\begin{array}{l}\theta_{1} \leq \hat{\theta}_{1} \\
\hat{\theta}_{1}<\theta_{1} \leq \theta_{1}^{*} \\
\theta_{1}^{*}<\theta_{1} \leq \bar{\theta}_{1} \\
\theta_{1}>\bar{\theta}_{1}\end{array}$ & $\begin{array}{l}(\mathrm{R}, \mathrm{D}, \mathrm{R}, \mathrm{R}) \\
(\mathrm{R}, \mathrm{R}, \mathrm{R}, \mathrm{R}) \\
(\mathrm{R}, \mathrm{R}, \mathrm{D}, \mathrm{NA}) \\
(\mathrm{D}, \mathrm{R}, \mathrm{D}, \mathrm{D}), F=\left[\pi_{R}^{R *}-\pi_{D}^{R *}, \pi_{D}^{M *}-\pi_{R}^{M *}\right]\end{array}$ \\
\hline & $\theta_{1}^{*} \geq \overline{\overline{\theta_{1}}}$ & $\begin{array}{l}\theta_{1} \leq \hat{\theta}_{1} \\
\hat{\theta}_{1}<\theta_{1} \leq \bar{\theta}_{1} \\
\bar{\theta}_{1}<\theta_{1} \leq \theta_{1}^{*} \\
\theta_{1}>\theta_{1}^{*}\end{array}$ & $\begin{array}{l}(\mathrm{R}, \mathrm{D}, \mathrm{R}, \mathrm{R}) \\
(\mathrm{R}, \mathrm{R}, \mathrm{R}, \mathrm{R}) \\
(\mathrm{D}, \mathrm{R}, \mathrm{R}, \mathrm{R}) \\
(\mathrm{D}, \mathrm{R}, \mathrm{D}, \mathrm{D}), F=\left[\pi_{R}^{R *}-\pi_{D}^{R *}, \pi_{D}^{M *}-\pi_{R}^{M *}\right]\end{array}$ \\
\hline \multirow[t]{3}{*}{$\hat{\theta_{1}}>\overline{\theta_{1}}$} & $\theta_{1}^{*} \leq \overline{\theta_{1}}$ & $\begin{array}{l}\theta_{1} \leq \theta_{1}^{*} \\
\theta_{1}^{*}<\theta_{1} \leq \bar{\theta}_{1} \\
\bar{\theta}_{1}<\theta_{1} \leq \hat{\theta}_{1} \\
\theta_{1}>\hat{\theta}_{1}\end{array}$ & $\begin{array}{l}(\mathrm{R}, \mathrm{D}, \mathrm{R}, \mathrm{R}) \\
(\mathrm{R}, \mathrm{D}, \mathrm{D}, \mathrm{D}), G=\left[\pi_{R}^{M *}-\pi_{D}^{M *}, \pi_{D}^{R *}-\pi_{R}^{R *}\right] \\
(\mathrm{D}, \mathrm{D}, \mathrm{D}, \mathrm{D}) \\
(\mathrm{D}, \mathrm{R}, \mathrm{D}, \mathrm{D}), F=\left[\pi_{R}^{R *}-\pi_{D}^{R *}, \pi_{D}^{M *}-\pi_{R}^{M *}\right]\end{array}$ \\
\hline & $\overline{\theta_{1}}<\theta_{1}^{*} \leq \hat{\theta}_{1}$ & $\begin{array}{l}\theta_{1} \leq \bar{\theta}_{1} \\
\bar{\theta}_{1}<\theta_{1} \leq \theta_{1}^{*} \\
\theta_{1}^{*}<\theta_{1} \leq \hat{\theta}_{1} \\
\theta_{1}>\hat{\theta}_{1}\end{array}$ & $\begin{array}{l}(\mathrm{R}, \mathrm{D}, \mathrm{R}, \mathrm{R}) \\
(\mathrm{D}, \mathrm{D}, \mathrm{R}, \mathrm{NA}) \\
(\mathrm{D}, \mathrm{D}, \mathrm{D}, \mathrm{D}) \\
(\mathrm{D}, \mathrm{R}, \mathrm{D}, \mathrm{D}), F=\left[\pi_{R}^{R *}-\pi_{D}^{R *}, \pi_{D}^{M *}-\pi_{R}^{M *}\right]\end{array}$ \\
\hline & $\theta_{1}^{*} \geq \hat{\theta_{1}}$ & $\begin{array}{l}\theta_{1} \leq \bar{\theta}_{1} \\
\bar{\theta}_{1}<\theta_{1} \leq \hat{\theta}_{1} \\
\hat{\theta}_{1}<\theta_{1} \leq \theta_{1}^{*} \\
\theta_{1}>\theta_{1}^{*}\end{array}$ & $\begin{array}{l}(\mathrm{R}, \mathrm{D}, \mathrm{R}, \mathrm{R}) \\
(\mathrm{D}, \mathrm{D}, \mathrm{R}, \mathrm{NA}) \\
(\mathrm{D}, \mathrm{R}, \mathrm{R}, \mathrm{R}) \\
(\mathrm{D}, \mathrm{R}, \mathrm{D}, \mathrm{D}), F=\left[\pi_{R}^{R *}-\pi_{D}^{R *}, \pi_{D}^{M *}-\pi_{R}^{M *}\right]\end{array}$ \\
\hline
\end{tabular}

Notes. The symbols "MF", "RF" and "SCF" denote the channel preference of the manufacturer, retailer and supply chain, respectively. "EC" denotes the equilibrium channel structure. The symbols "D" and "R" denote dual channels and retail channel, respectively. The symbol "F" denotes the fees the manufacturer pays to the retailer and "G" denotes the fees the retailer pays to the manufacturer. "NA" stands for not applicable. 


\section{REFERENCES}

[1] Y. Alan and V. Gaur, Operational investment and capital structure under asset-based lending. Manuf. Serv. Oper. Manage. 20 (2018) 637-654.

[2] F. Alawneh and G. Zhang, Dual-channel warehouse and inventory management with stochastic demand. Transp. Res. E-Log. 112 (2018) 84-106.

[3] O. Baron, O. Berman and D. Wu, Bargaining within the supply chain and its implications in an industry. Dec. Sci. 47 (2016) $193-218$.

[4] P. Bhardwaj, Delegating pricing decisions. Mark. Sci. 20 (2001) 143-169.

[5] G.S. Cai, Channel selection and coordination in dual-channel supply chains. J. Retail. 86 (2010) 22-36.

[6] G.G. Cai, Z.G. Zhang and M. Zhang, Game theoretical perspectives on dual-channel supply chain competition with price discounts and pricing schemes. Int. J. Prod. Econ. 117 (2009) 80-96.

[7] G.G. Cai, X. Chen and Z. Xiao, The roles of bank and trade credits: theoretical analysis and empirical evidence. Prod. Oper. Manag. 23 (2014) 583-598.

[8] K. Cattani, W. Gilland, H.S. Heese and J. Swaminathan, Boiling frogs: pricing strategies for a manufacturer adding a direct channel that competes with the traditional channel. Prod. Oper. Manag. 15 (2006) 40-56.

[9] M.S. Chern, Q. Pan, J.T. Teng, Y.L. Chan and S.C. Chen, Stackelberg solution in a vendor-buyer supply chain model with permissible delay in payments. Int. J. Prod. Econ. 144 (2013) 397-404.

[10] X.F. Chen, A model of trade credit in a capital-constrained distribution channel. Int. J. Prod. Econ. 59 (2015) $347-357$.

[11] X.F. Chen and G.H. Wan, The effect of financing on a budget-constrained supply chain under wholesale price contract. Asia. Pac. J. Oper. Res. 28 (2011) 457-485.

[12] J. Chen, H. Zhang and Y. Sun, Implementing coordination contracts in a manufacturer Stackelberg dual-channel supply chain. Omega 40 (2012) 571-583.

[13] X. Chen, H. Zhang, M. Zhang and J. Chen, Optimal decisions in a retailer Stackelberg supply chain. Int. J. Prod. Econ. 187 (2017) 260-270.

[14] X.F. Chen, G.S. Cai and J.S. Song, The cash flow advantages of 3PLs as supply chain orchestrators. Manuf. Serv. Oper. Manage. 21 (2019) 435-451.

[15] J. Chod, E. Lyandres and S.A. Yang, Trade credit and supplier competition. J. Finan. Econ. 131 (2019) $484-505$.

[16] M. Dada and Q.J. Hu, Financing the newsvendor inventory. Oper. Res. Lett. 36 (2008) 269-273.

[17] S. Deng, C. Gu, G. Cai and Y. Li, Financing multiple heterogeneous suppliers in assembly systems: buyer finance vs. bank finance. Manuf. Serv. Oper. Manage. 20 (2018) 53-69.

[18] Q. Ding, C. Dong and Z. Pan, A hierarchical pricing decision process on a dual-channel problem with one manufacturer and one retailer. Int. J. Prod. Econ. 175 (2016) 197-212.

[19] A. Dumrongsiri, M. Fan and A. Jain, A supply chain model with direct and retail channels. Eur. J. Oper. Res. 187 (2008) 691-718.

[20] Q. Feng, G. Lai and L.X. Lu, Dynamic bargaining in a supply chain with asymmetric demand information. Manage. Sci. 61 (2014) 301-315.

[21] X. Guan and Y.J. Chen, The Interplay between information acquisition and quality disclosure. Prod. Oper. Manag. 26 (2017) 389-408.

[22] B.W. Goh, C.Y. Lim, G.J. Lobo and Y.H. Tong, Conditional conservatism and debt versus equity financing. Contemp. Account. Res. 34 (2017) 216-251.

[23] L. Guo and G. Iyer, Multilateral bargaining and downstream competition. Mark. Sci. 32 (2013) 411-430.

[24] A. Ha, S. Tong and H. Zhang, Sharing demand information in competing supply chains with production diseconomies. Manage. Sci. 57 (2011) 566-581.

[25] S.H. Han, Y.F. Fu and B. Cao, Pricing and bargaining strategy of e-retail under hybrid operational patterns. Ann. Oper. Res. 270 (2018) 179-200.

[26] J. Huang, W. Yang and Y. Tu, Supplier credit guarantee loan in supply chain with financial constraint and bargaining. Int. J. Prod. Res. 57 (2019) 7158-7173.

[27] G. Iyer and J.M. Villas-Boas, A bargaining theory of distribution channels. J. Marketing. Res. 40 (2003) 80-100.

[28] B. Jing, X.F. Chen and G. Cai, Equilibrium financing in a distribution channel with capital constraint. Prod. Oper. Manag. 21 (2012) 1090-1101.

[29] P. Kouvelis and W. Zhao, Financing the newsvendor: supplier vs. bank, and the structure of optimal trade credit contracts. Oper. Res. 60 (2012) 566-580.

[30] N. Kumar and R. Ruan, On manufacturers complementing the traditional retail channel with a direct online channel. Quant. Mark. Econ. 4 (2006) 289-323.

[31] Y. Kusnadi and K.C. John-Wei, The equity-financing channel, the catering channel, and corporate investment: international evidence. J. Corp. Financ. 47 (2017) 236-252.

[32] M. Li and T. Li, Consumer search, transshipment, and bargaining power in a supply chain. Int. J. Prod. Res. 56 (2018) 3423-3438.

[33] B. Li, P.W. Hou, P. Chen and Q.H. Li, Pricing strategy and coordination in a dual channel supply chain with a risk-averse retailer. Int. J. Prod. Econ. 178 (2016) 154-168. 
[34] G. Li, H.M. Wu and S. Xiao, Financing strategies for a capital-constrained manufacturer in a dual-channel supply chain. Int. Trans. Oper. Res. 27 (2020) 2317-2339.

[35] W. Lovejoy, Bargaining chains. Manage. Sci. 56 (2010) 2282-2301.

[36] L. Ma, F. Liu, S. Li and H. Yan, Channel bargaining with risk-averse retailer. Int. J. Prod. Econ. 139 (2012) $155-167$.

[37] W. Missaka and M.W. Toni, Equity market misvaluation, financing and investment. Rev. Financial Stud. 29 (2016) $603-654$.

[38] J.J. Qin, L.G. Ren, L.J. Xia, Z.P. Wang and H.D. Chang, Pricing strategies for dual-channel supply chains under a trade credit policy. Int. T. Oper. Res. 27 (2020) 2469-2508.

[39] Q. Qing, T. Deng and H. Wang, Capacity allocation under downstream competition and bargaining. Eur. J. Oper. Res. 261 (2017) 97-107.

[40] M. Radhi and G. Zhang, Optimal cross-channel return policy in dual-channel retailing systems. Int. J. Prod. Econ. 210 (2019) $184-198$.

[41] Z.B. Wang, Y.Y. Wang and J.C. Wang, Optimal distribution channel strategy for new and remanufactured products. Electron. Commer. Res. 16 (2016) 269-295.

[42] C. Wang, X. Fan and Z. Yin, Financing online retailers: bank vs. electronic business platform, equilibrium, and coordinating strategy. Eur. J. Oper. Res. 276 (2019) 343-356.

[43] D. Wu, B.F. Zhang and O. Baron, A trade credit model with asymmetric competing retailers. Prod. Oper. Manag. 28 (2019) 206-231.

[44] N.N. Yan, B.W. Sun, H. Zhang and C.Q. Liu, A partial credit guarantee contract in a capital-constrained supply chain: financing equilibrium and coordinating strategy. Int. J. Prod. Econ. 173 (2016) 122-133.

[45] N.N. Yan, X.L. He and Y. Liu, Financing the capital-constrained supply chain with loss aversion: supplier finance vs. supplier investment. Omega. 88 (2019) 162-178.

[46] N. Yan, Y. Liu, X. Xu and X. He, Strategic Dual-channel Pricing Games with E-retailer Finance. Eur. J. Oper. Res. 283 (2020) 138-151.

[47] H.L. Yang, W.Y. Zhuo and L.S. Shao, Equilibrium evolution in a two-echelon supply chain with financially constrained retailers: the impact of equity financing. Int. J. Prod. Econ. 185 (2017) 139-149.

[48] S.A. Yang and J.R. Birge, Trade credit, risk sharing, and inventory financing portfolios. Manage. Sci. 64 (2018) $3667-3689$.

[49] S. Yang, V. Shi and J.E. Jackson, Manufacturers' channel structures when selling asymmetric competing products. Int. J. Prod. Econ. 170 (2015) 641-651.

[50] H.X. Yang, J.W. Luo and Q.H. Zhang, Supplier encroachment under nonlinear pricing with imperfect substitutes: bargaining power versus revenue-sharing. Eur. J. Oper. Res. 267 (2018) 1089-1101.

[51] X.P. Zhen, D. Shi, Y.J. Li and C. Zhang, Manufacturer's financing strategy in a dual-channel supply chain: third-party platform, bank and retailer credit financing. Transp. Res. E-Log. Transp. Rev. 133 (2020) 101820.

[52] F. Zhong, J. Xie, X. Zhao and Z.J.M. Shen, On efficiency of multistage channel with bargaining over wholesale prices. Nav. Res. Log. 63 (2016) 449-459. 